\title{
Moving towards socio-technical scenarios of the German energy transition - lessons learned from integrated energy scenario building
}

Thomas Pregger a,*, Tobias Naegler a, Wolfgang Weimer-Jehle b, Sigrid Prehofer b, Wolfgang Hauser b a Department of Energy Systems Analysis, Institute of Engineering Thermodynamics, German Aerospace Center (DLR), Stuttgart, Germany

b Center for Interdisciplinary Risk and Innovation Studies (ZIRIUS), University of Stuttgart, Germany * corresponding author

\section{Supplementary Material (SM)}

\section{SM-(1) Overview about the workflow of the scenario analysis}

Storyline construction

Hybrid products

Descriptor list

(literature / experts)
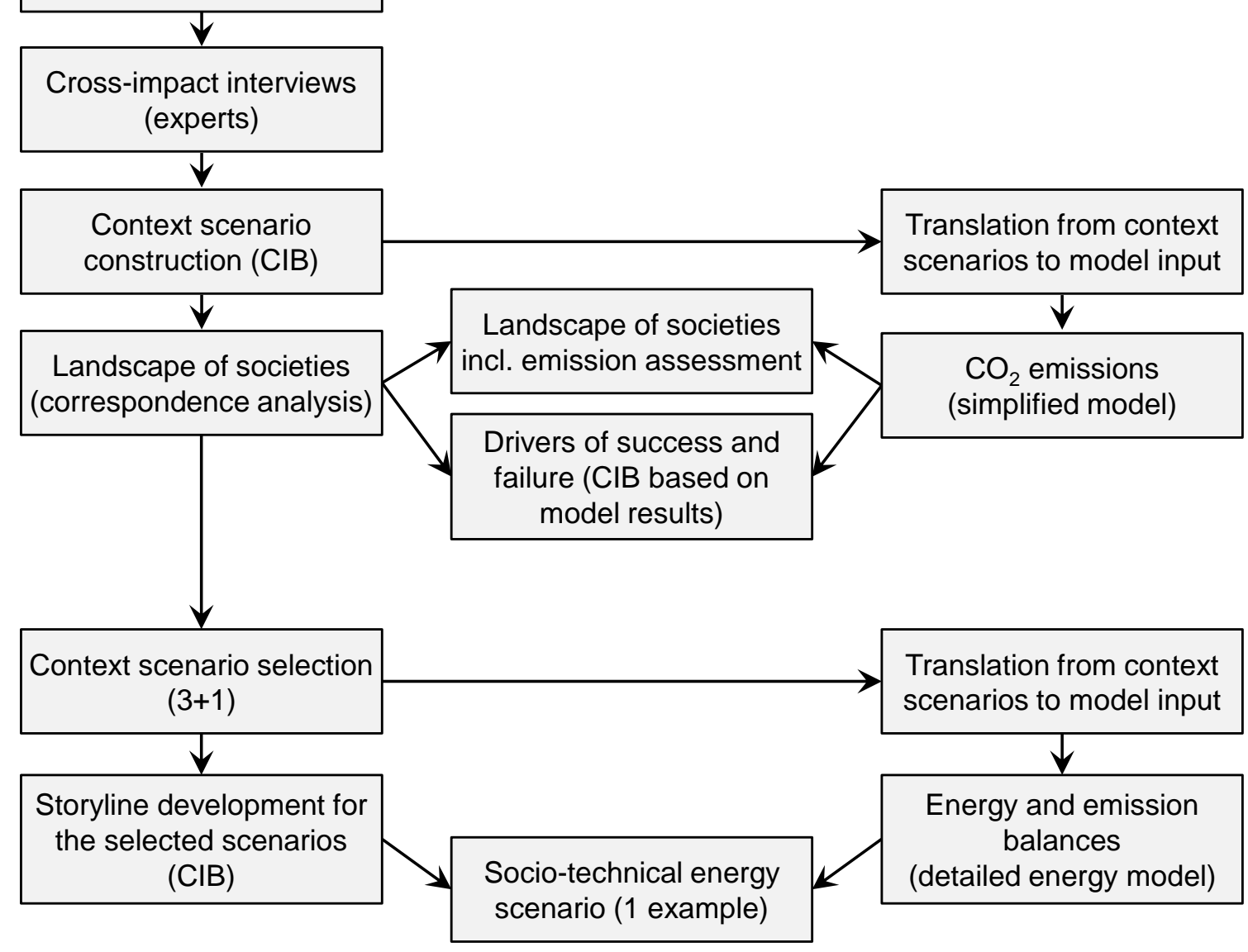

Figure 1: Workflow of the integrated scenario analysis. 


\section{SM-(2) Data survey design}

CIB context scenarios can be more or less constructed over four steps:

1. context definitions (finding descriptors),

2. definition of uncertainty (describing different descriptor developments),

3. interdependency analysis (survey of cross-impact judgments) and finally

4. the construction of context scenarios (applying the balance algorithm to generate consistent scenarios) (Weimer-Jehle et al. 2016)

The operationalization of these steps can be done very differently. This case describes a rather comprehensive application of the context scenario approach, meaning that a considerable amount of data was collected, processed and reflected. Thus, the methodology for generating context scenarios of the German energy system involved applying many additional methods and steps for each of the abovementioned ones. They are described as follows.

\section{Step 1)}

The selection of descriptors for analysis is a very important step, as they determine which aspects of a context are considered and excluded. Therefore, this step was considered carefully and with much deliberation. We adopted a 5-step procedure to produce the final descriptor list. Without describing the steps in detail, a short overview is provided below.

To define energy transition context:

i) A literature review of 45 scenarios (societal, energy,...) was conducted and descriptors used were filtered and analyzed (Gallego Carrera et al, 2013). This formed the basis for the

ii) 23 unstructured expert interviews, which were mainly carried out with interdisciplinary ENERGY-TRANS experts. Out of the 19 projects executed in ENERGYTRANS, 17 involved descriptor consultation. All of the interviews were recorded and were processed afterwards. The descriptor list developed was then refined and structured by

iii) applying sociological theory and a developed structuring tool (Prehofer, forthcoming). As a final step, descriptors were selected and

iv) an expert rating was applied to form the basis of

v) additional selection criteria. Twenty-eight ENERGY-TRANS experts representing seven 'disciplines' (energy economics, economics, politics, law, sociology, psychology, and 'comprehensive topics') and 16 of the 19 ENERGY-TRANS projects participated. In addition to the expert rating, selection rules about 'must-haves for modelers', 'theoretical completeness', 'balance between context and energy descriptors' and 'balance between disciplinary participation' were applied to compile the final descriptor list of 39 descriptors (a complete list of the descriptors used can be found in Weimer-Jehle, Prehofer, Hauser (2015)).

Step 2)

For all 39 descriptors, short essays were prepared on the basis of a

i) literature review and

ii) written reviews of domain experts to describe the content of each social and technical descriptor. To take account of future uncertainties, two to four plausible future developments for each descriptor were defined depending on the 'bandwidth' of uncertainty determined from our literature review and from domain experts (all of the descriptors are described in Weimer-Jehle, Prehofer, Hauser (2015)). 
Fifteen of the 39 descriptors are quantitative in nature and needed to be quantified for modeling purposes. For this project we decided to find quantifications for the different future variables in this early phase of scenario construction (i.e., before judgments on interrelations are made). In turn, the experts could make judgments on the basis of concrete numbers and not only based on qualitative concepts. To apply adequate quantifications representing future uncertainties, we

i) searched for quantifications used in existing energy scenario studies. As a result we were able to assess the bandwidth of uncertainty estimated for the energy scenario community. Using these bandwidths, we

ii) adopted the applied quantifications to the descriptor developments. As a last step we

iii) discussed and refined these quantifications in cooperation with the modelers of this project.

\section{Step 3)}

Expert judgments about the interdependencies between all descriptor developments ("cross-impacts") are the core of our data survey. To collect these expert judgments we

i) conducted 1-3 two-hour interviews per descriptor with domain experts (67 in total) with knowledge of a specific field. This allowed not only for the integration of an enormous amount of domains and of appropriate descriptors but also of different experts' opinions. To obtain more valid statements,

ii) the domain experts of each separate descriptor were allowed to underpin or adapt their judgments through a Delphi-style consultation (i.e., when divergent judgments emerged (divergent signs) the experts were informed of the judgments and explanations of the other experts and were asked to reconsider their statements). Finally, the context scenario team

iii) checked and in certain cases concretized impact judgments due to their methodical correctness.

\section{Step 4)}

The above steps build the basis for the final construction of consistent context scenarios. Thirty-nine descriptors with a total of 108 futures represent societal and energy-related topics. More precisely, the considered system includes 4 international, 10 economic, 6 political, 5 societal, 3 cultural and 11 energy-related descriptors, creating approximately $10^{14}$ possible scenario configurations for the context descriptors (approximately $3 \cdot 10^{18}$ when the eleven energy related descriptors are included). To limit the configuration set to consistent scenarios, the

i) balance algorithm of the CIB is applied (cf. Weimer-Jehle 2006) to identify 182 fully consistent scenarios (1725 scenarios when fully and nearly consistent scenarios are accepted) based on the impact judgments of the expert interviews. Still, the number of consistent scenarios is high and not each of those could be calculated in detail using the energy model. Thus, to select scenarios for the modeling exercise illuminating different facets of the societal possibility space,

ii) some additional methods are applied to explore the context and its interrelations with the energy system in more depth. This is described in more detail in chapter 3 of the article.

The expert elicitation process designed and applied for our project to prepare a descriptor list can be compared to expert processes used in other CIB studies. For instance, Schweizer and O'Neil (2014) based their descriptor selection method on an online survey inviting 74 experts to participate, 25 of whom responded. The experts were given a list of socioeconomic factors and were asked to prioritize them (the prioritization of multiple factors was allowed). After the survey was completed, the percent- 
age of respondents prioritizing a factor was calculated, and all factors selected by at least $25 \%$ of the respondents were included in the study.

Procedures applied by Schweizer and O'Neil and in our study are similar in their basic approaches. A difference lies in the inclusion of measures applied in our study to balance the number of descriptors addressing different science domains. This is the case due to our goal of representing both societal and energy futures in our scenarios and the very broad range of science domains to be covered to this aim. As we relied on the ENERGY-TRANS team (approx. 60 persons) for descriptor prioritization (yet not for the cross-impact interviews) and as science domains were not equally represented by the team, biases in the representation of science domains included in the descriptor list may have occurred without the use of balancing measures.

A remarkably different approach is presented by Kemp-Benedict et al. (2014). The authors aimed at finding a list of prerequisites for sustainable forest management to be used as a descriptor list. They applied text analysis software to search through SSP (shared socio-economic pathway) storylines and related documents for respective text elements. The list of prerequisites gained by this analysis was edited to exclude factors that can be expected to be dominated by other factors. The resulting list was used for the CIB analysis.

This approach is less subjective and can be used to exploit large knowledge databases. It is an innovative approach that will likely be used more in CIB studies in the future, as it renders CIB studies more independent from (direct) expert elicitation. Schweizer and Kriegler (2012) also showed that crossimpact data can be derived (at least on some topics) from a literature review. The approach may present also challenges when applied for context scenario analysis. As one challenge text analysis can be expected to reveal direct drivers of a system under investigation but it may struggle to find indirect ones, which are the specific focus of a context scenario analysis. Another challenge emerges when a CIB study is designed to motivate experts to reconsider a problem and to identify 'unconventional' connections between science domains, as a text analysis can only return connections already recognized by scholars. However, such challenges may in part be remedied by the use of appropriate analysis methods or advantages may be found to overweigh related challenges.

\section{References:}

Gallego Carrera D, Ruddat M. Rothmund S (2013) Societal influence factors on the energy sector empirical results from the analysis of 45 scenario studies [in German]. Stuttgart contributions to risk and sustainability research Vol. 27, University of Stuttgart.

Kemp-Benedict E, de Jong W, Pacheco P (2014) Forest futures: Linking global paths to local conditions. In Katila P., Galloway G., de Jong W., Pacheco P., Mery G. (eds.): Forest under pressure - Local responses to global issues. Part IV - Possible future pathways. IUFRO World Series Vol. 32, 539-53.

Prehofer S (2018) Dissertation draft (in preparation). University of Stuttgart.

Schweizer VJ, Kriegler E (2012) Improving environmental change research with systematic techniques for qualitative scenarios. Environ. Res. Lett. 7.

Schweizer VJ, O’Neill BC (2014) Systematic construction of global socioeconomic pathways using internally consistent element combinations. Climatic Change 122:431-45.

For more references see main text. 


\section{SM-(3) List of experts involved in the cross-impact interviews}

Experts participating in the descriptor identification survey

Gregor Betz

Robert Brandt

Jens Buchgeister

Marc Deissenroth

Gerhard Fuchs

Armin Grunwald

Volker M. Haug

N.N.

Max Kleemann

Wolfgang Köck

Jürgen Kopfmüller

Paul Lehmann

Georg Licht

N.N.

Birgit Mack

Ellen Matthies

Tobias Naegler

Michael Nast

Dörte Ohlhorst

Witold-Roger Poganietz

Thomas Pregger

Ortwin Renn

Klaus Rennings

Andreas Rieder

Christine Rösch

Jens Schippl

Yvonne Scholz

Pia-Johanna Schweizer

Kerstin Tews

Elke Uhl

Stefan Vögele

Sandra Wassermann

Annika Weiss
Karlsruhe Institute of Technology / ITAS

Free University of Berlin

Karlsruhe Institute of Technology / ITAS

German Aerospace Center (DLR), Stuttgart / TT-STB

University of Stuttgart / ZIRIUS

Karlsruhe Institute of Technology / ITAS

University of Stuttgart / Institute of Economy and Law

Karlsruhe Institute of Technology / ITAS

Center for Environmental Research, Leipzig (UFZ) / EP

Karlsruhe Institute of Technology / ITAS

Center for Environmental Research, Leipzig (UFZ) / Economy

Centre for European Economic Research (ZEW), Mannheim

University of Stuttgart / ZIRIUS

University of Magdeburg

German Aerospace Center (DLR), Stuttgart / TT-STB

German Aerospace Center (DLR), Stuttgart / TT-STB

Free University of Berlin

Karlsruhe Institute of Technology / ITAS

German Aerospace Center (DLR), Stuttgart / TT-STB

University of Stuttgart / ZIRIUS

Centre for European Economic Research (ZEW)

Karlsruhe Institute of Technology / ITAS

Karlsruhe Institute of Technology / ITAS

Karlsruhe Institute of Technology / ITAS

German Aerospace Center (DLR), Stuttgart / TT-STB

University of Stuttgart / ZIRIUS

Free University of Berlin

University of Stuttgart / IZTK

Research Center Jülich (FZJ) / STE

University of Stuttgart / ZIRIUS

Karlsruhe Institute of Technology / ITAS 
Experts interviewed for cross-impact matrix construction:

Marian Adolf

Christian Arndt

Annika Arnold

Timo Baas

Stefan Bach

Sophia Becker

Martin Biewen

Frieder Borggrefe

Jens Buchgeister

Marc Deissenroth

Thomas Eckert

Henriette Engelhardt-Wölfler

Gerhard Fuchs

Julian Hahmann

Patrick Hansen

Eva Hauser

Dirk Heinrichs

Reiner Höft-Dzemski

Patrick Jochem

Max Kleemann

Wolfgang Köck

Wilhelm Kohler

Raimund Krumm

Paul Lehmann

N.N.

Birgit Mack

Ellen Matthies

Tobias Naegler

Dörte Ohlhorst

Ilona Ostner

N.N.

Gerhard Pfister

Thomas Pregger

Andreas Pyka

Wilhelm Rall
Zeppelin University

Nürtingen-Geislingen University (HfWU)

University of Stuttgart / ZIRIUS

University of Duisburg-Essen

German Institute for Economic Research (DIW), Berlin

University of Stuttgart / ZIRIUS

University of Tübingen

German Aerospace Center (DLR), Stuttgart / TT-STB

Karlsruhe Institute of Technology / ITAS

German Aerospace Center (DLR), Stuttgart / TT-STB

Ludwig-Maximilian University München

University of Bamberg, Chair for Demography

University of Stuttgart, Institute of Social Sciences

Friedrich-Wilhelms-University Bonn

Research Center Jülich (FZJ) / STE

Institute for Sustainable Energy and Material Flow Systems (IZES)

German Aerospace Center (DLR), Berlin / VF

German Association for Public and Private Welfare, Berlin

Karlsruhe Institute of Technology / LfE

Karlsruhe Institute of Technology / ITAS

Center for Environmental Research, Leipzig (UFZ) / PP

University of Tübingen, International Economie

Institute of Applied Economic Research (IAW), Tübingen

Center for Environmental Research, Leipzig (UFZ) / Economy

University of Stuttgart / ZIRIUS

University of Magdeburg

German Aerospace Center (DLR), Stuttgart / TT-STB

Free University of Berlin / FFU

Georg-August-University, Göttingen

Nürtingen-Geislingen University (HfWU)

German Aerospace Center (DLR), Stuttgart / TT-STB

University of Hohenheim

McKinsey 
Mathias Reeg

Ortwin Renn

Klaus Rennings

Mike Schäfer

Susanne Schmid

Dominik Schober

Yvonne Scholz

Regina Schröter

Sophia Schubert

Kai Schulze

Karin Schürmann

Pia-Johanna Schweizer

Katrin Sommerfeld

Sibyl Steuwer

N.N.

Kerstin Tews

Matthias Toups

Stefan Vögele

Gisela Wachinger

Sandra Wassermann

Johannes Weyer

Oliver Woll

Michael Zwick
German Aerospace Center (DLR), Stuttgart / TT-STB

University of Stuttgart / ZIRIUS

Centre for European Economic Research (ZEW), Mannheim

University of Zürich UZH

University of Stuttgart / Institute of Economy and Law

Centre for European Economic Research (ZEW), Mannheim

German Aerospace Center (DLR), Stuttgart / TT-STB

University of Stuttgart / ZIRIUS

Free University of Berlin

University of Potsdam

Research Center Jülich (FZJ) / STE

University of Stuttgart / ZIRIUS

Centre for European Economic Research (ZEW), Mannheim

Free University of Berlin / FFU

Free University of Berlin / FFU

German Aerospace Center (DLR), Berlin / VF

Research Center Jülich (FZJ) / STE

University of Stuttgart / ZIRIUS

University of Stuttgart / ZIRIUS

University of Dortmund

Centre for European Economic Research (ZEW), Mannheim

University of Stuttgart / ZIRIUS

N.N. represents experts asking for anonymity 


\section{SM-(4) Description of pole representative selection (main text, chapter 3)}

For in depth modeling, three scenarios out of the full set of 1725 context scenarios were used to represent poles of societal landscapes of the 'Inertia', 'Market' and 'Value Shift' scenarios (see Fig. 2 of the main text). Each representative was selected from all scenarios in the vicinity of each pole. The selection procedure was as follows: For each pole,

- Step 1: Frequencies of the descriptor developments based on all scenarios in the vicinity of the pole were calculated.

- Step 2: As an indicator for being typical for the pole vicinity, the sum of frequencies of all descriptors was calculated for each scenario in the pole vicinity.

- Step 3: the scenario with the highest indicator value was chosen to represent the pole.

This procedure prevents one from selecting a scenario that is rather untypical of a given pole vicinity. Nevertheless, there are heterogeneities within each pole vicinity and the representative quality of each scenario is limited but optimized by the selection procedure.

\section{SM-(5) Approach used to couple context scenarios with the energy system model}

The following considerations apply for both the simplified scenario calculation tool based on Microsoft Excel and the scenario development method employed using Mesap/PlaNet (unless otherwise stated).

\section{General comments}

Our coupling of context scenarios with the energy model was based on four different principles on determining technical scenario parameters, which differ in how they are determined by the given context scenario:

1. Coupling of 'hard' coupling factors: 'Hard' coupling factors are context descriptors that directly determine a quantitative model parameter. 'Hard' coupling factors can for instance cover the total amount of renewable electricity or heat supplied in 2050 or the average development of energy intensities of different sectors for 2015 to 2050. 'Hard' coupling factors leave very limited room for scenario modeler interpretations.

2. Coupling of 'soft' coupling factors: In contrast to 'hard' coupling factors, 'soft' coupling factors do not directly correspond with a (quantitative) model parameter. However, 'soft' coupling factors show a clear relationship to quantitative model parameters such that a plausible interpretation can be made based on background knowledge. One example is context descriptor 'central or decentralized electricity generation and storage', which can be interpreted in terms of the technology mix for electricity generation (see below). Although the interpretation of 'soft' coupling factors in terms of scenario parameters leaves room for modeler interpretation, his choice of parameter values must be well justified.

3. Determination of relevant scenario parameters not considered by the context scenario: Context scenarios do not determine most parameters relevant to further describe the technical storyline of the given scenario. Such undetermined parameters cover, e.g., the technology mix of conventional power plants or of heat generation technologies, the blending quotas of biofuels, etc. For such parameters, two different approaches can be applied:

i. For some parameters (e.g., shares of individual conventional power generation technologies of total conventional power generation), plausible values can be chosen 
based on technical constraints of the power system (e.g., rising demand for flexible power generation with rising shares of intermittent renewables, which are well identified from other more detailed scenario modeling studies). As a consequence, room for scenario modeler interpretation is limited.

ii. Values for other parameters (e.g., the blending quota for biofuels) have to be chosen according to the 'spirit' of the given scenario (e.g., societal views of nature conservation). In these cases, there is more room for modeler interpretation than in the cases discussed above.

4. Determination of techno-economic parameters of energy technologies: The technoeconomic parameters for all relevant energy technologies (e.g., efficiencies or specific investment costs for power generation, heat generation, cogeneration, power-to-gas systems, transport technologies, etc.) are identical across all scenarios and are based on DLR's standard techno-economic database on energy technologies (see, e.g., Nitsch et al. (2012) and Pregger et al. (2013)). The only exceptions are descriptors (b) and (c) (reduction of the specific energy demand of electric vehicles and of vehicles with combustion engines), which are adjusted according to the context scenario.

In the paragraphs below we discuss the coupling of 'hard' and 'soft' coupling factors with the scenario model and our determination of parameter values in more detail.

\section{Information on 'hard' and 'soft' coupling factors in this study}

Table 1 to Table 4 document variants of all context descriptors for all four scenarios considered (the 'Target, 'Inertia', 'Market Forces', and 'Value Shift' scenarios). Hard coupling factors are highlighted in dark grey and soft coupling factors are highlighted in light grey. Further information on the coupling of hard/soft coupling factors with the scenario model is given for each descriptor.

\section{descriptor A(II): 'global fossil price pathway'}

Soft coupling factor. This descriptor refers to the international market price of 1 barrel of crude oil, but it is used to describe trends in the development of prices for all fossil fuels including natural gas, hard coal and diesel/gasoline for end users. For each of the three variants $(100 \$ / \mathrm{bbl}, 166 \$ / \mathrm{bbl}$, and $210 \$ / b b l)$, a corresponding price for those fossil energy carriers is assumed. However, price effects are not discussed in the paper.

\section{descriptor A(III): 'global interest rate'}

Hard coupling factor. This factor is used to calculate capital costs of energy technologies in the model. However, price effects are not discussed in the paper.

\section{descriptor C: 'population'}

Hard coupling factor. This factor is used to calculate living space, energy demand for space heat and electric applications in households, and passenger transport services.

\section{descriptor D: 'GDP growth'}

Hard coupling factor. 'GDP growth' determines (in combination with descriptor F 'tertiarization of the economy') the growth of value added in the industrial, trade and commerce sectors and thus indirectly the final energy demand of these sectors.

\section{descriptor F: 'tertiarization of the economy'}

Soft coupling factor. All scenarios assume that only $20 \%$ of all jobs are of the industrial sector, which corresponds to $27 \%$ of the gross value added (GVA). 


\section{descriptor K: 'expansion of renewable energies in the electricity sector'}

Hard coupling factor. This determines power generation from renewable sources in the model. However, the share of individual technologies is also determined by descriptor L 'central/decentralized electricity generation and storage') (see below).

\section{descriptor L: 'central/decentralized electricity generation and storage'}

Soft coupling factor. All scenarios assume an increase in renewable electricity generation. The 'trend towards central electricity generation and storage' is thus interpreted as a trend towards the use of offshore wind and large onshore wind parks and central (public) cogeneration plants, whereas a trend towards 'decentralized electricity generation and storage' is interpreted as a trend towards PV and decentralized cogeneration use in households and small enterprises.

\section{descriptor a: 'reduction energy demand - household appliances'}

Hard coupling factor. This descriptor describes the development of per-capita electricity demand in private households. In combination with population development it determines the power demand of private households for electric applications (no heating or transport).

\section{descriptor b: 'reduction energy demand - PC electric vehicles'}

Hard coupling factor. This descriptor describes the reduction of average specific energy demand (per passenger kilometer) of an electric vehicle fleet (passenger cars, BEVs, PHEVs and hydrogen fuel cell electric vehicles). In combination with the development of passenger transport services and the share of 'new' cars in the passenger vehicle fleet (see descriptor $h$ 'investment in new vehicle concepts and infrastructure'), it determines the power and hydrogen demand of individual passenger transport.

\section{descriptor c: 'reduction in energy demand - PC engines'}

Hard coupling factor. This descriptor describes the reduction in the average specific energy demand (per passenger kilometer) of internal combustion engines of private cars. In combination with the development of passenger transport services and the share of 'new' cars in the passenger vehicle fleet (see descriptor $\mathrm{h}$ 'investment in new vehicle concepts and infrastructure'), it determines the gasoline and diesel demand of individual passenger transport.

\section{descriptor d(I): 'renovation rate - buildings (private)'}

Soft coupling factor. In combination with descriptor d(II), descriptor d(I) determines specific energy demand for space heating in private houses. In combination with descriptors C ('population development' and i ('living trends'), this determines final energy demand for space heating in private households.

At an annual renovation rate of $1 \%$ and a renovation depth of $30 \%$ (reduction of specific energy demand per living space due to renovation), we assume that the average specific energy demand per living space of the building stock can be reduced to $100 \mathrm{kWh} / \mathrm{m}^{2} / \mathrm{yr}$ (from today's value of $150 \mathrm{kWh} / \mathrm{m}^{2} / \mathrm{yr}$ ). At a renovation rate of $1.5 \%$ and a renovation depth of $50 \%$, the specific energy demand can be reduced to $76 \mathrm{kWh} / \mathrm{m}^{2} / \mathrm{yr}$, and at a renovation rate of $2 \%$ and a renovation depth of $70 \%$, the average specific energy demand of the building stock can be reduced to $41 \mathrm{kWh} / \mathrm{m}^{2} / \mathrm{yr}$ by 2050 .

\section{descriptor d(II): 'renovation depth - buildings (private)'}

Soft coupling factor. See descriptor d(I).

\section{descriptor e: 'reduction of energy demand - industry'}

Hard coupling factor. This descriptor describes the reduction in the energy intensity (final energy demand per gross value added) of the German industry. In combination with descriptors D ('GDP development') and E ('tertiarization of the economy') it allows one to estimate the final energy demand of the industry. 
descriptor f: 'reduction of energy demand - commercial sector'

Hard coupling factor, similar to descriptor e.

\section{descriptor g: 'expansion of district heating'}

Soft coupling factor. Descriptor variant 'no change' is interpreted as a continuation of the current stagnation of district heating (ca. $500 \mathrm{PJ} / \mathrm{yr}$ in Germany) and as an eventual reduction due to reduced space heating demand. Descriptor variant 'strong expansion' implies an increase in public district heating generation to $600-700 \mathrm{PJ} / \mathrm{yr}$.

\section{descriptor h: 'investment in new vehicle concepts and infrastructures'}

Hard coupling factor. This descriptor directly describes the share of 'new' technologies (BEVs, PHEVs, and hydrogen fuel cell vehicles) of all transport services of individual passenger cars.

\section{descriptor i: 'living trends'}

Hard coupling factor. In combination with descriptor C ('population development'), the descriptor determines living spaces and in turn in combination with descriptors $\mathrm{d}(\mathrm{I})$ and $\mathrm{d}(\mathrm{II})$ final energy demand for space heating in private households.

\section{descriptor j: 'expansion of renewables for heating'}

Hard coupling factor. In combination with descriptor $g$ ('expansion of district heating'), descriptor $\mathrm{j}$ determines the expansion of renewable heat (in $\mathrm{TWh} / \mathrm{yr}$ ) for individual buildings (heat pumps, biomass, and solar thermal) and district heating (biomass, solar thermal, geothermal and heat pumps).

\section{descriptor $k$ : 'rebound effects of individual energy demand'}

Soft coupling factor. In the case of a 'moderate rebound', the energy demand of private households (electric appliances) is $7 \%$ higher than in the case of a 'small rebound'. In the case of a 'strong rebound', energy demand for electric appliances used in private households is $15 \%$ higher than that of the 'small rebound' case. 


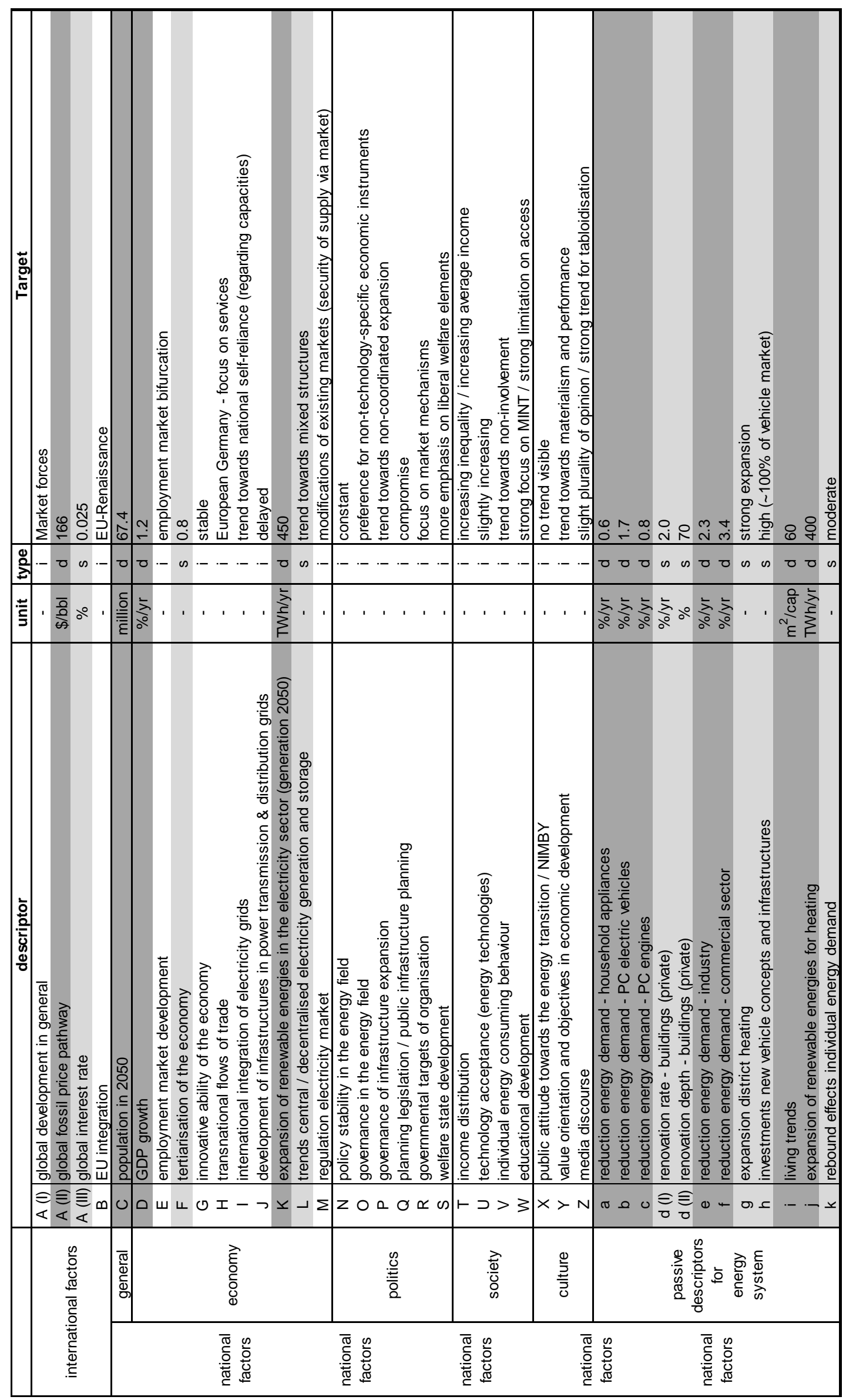

Table 1: Descriptor variants for the 'Target' scenario (direct/hard coupling descriptors highlighted in dark grey, soft coupling descriptors highlighted in light grey). 


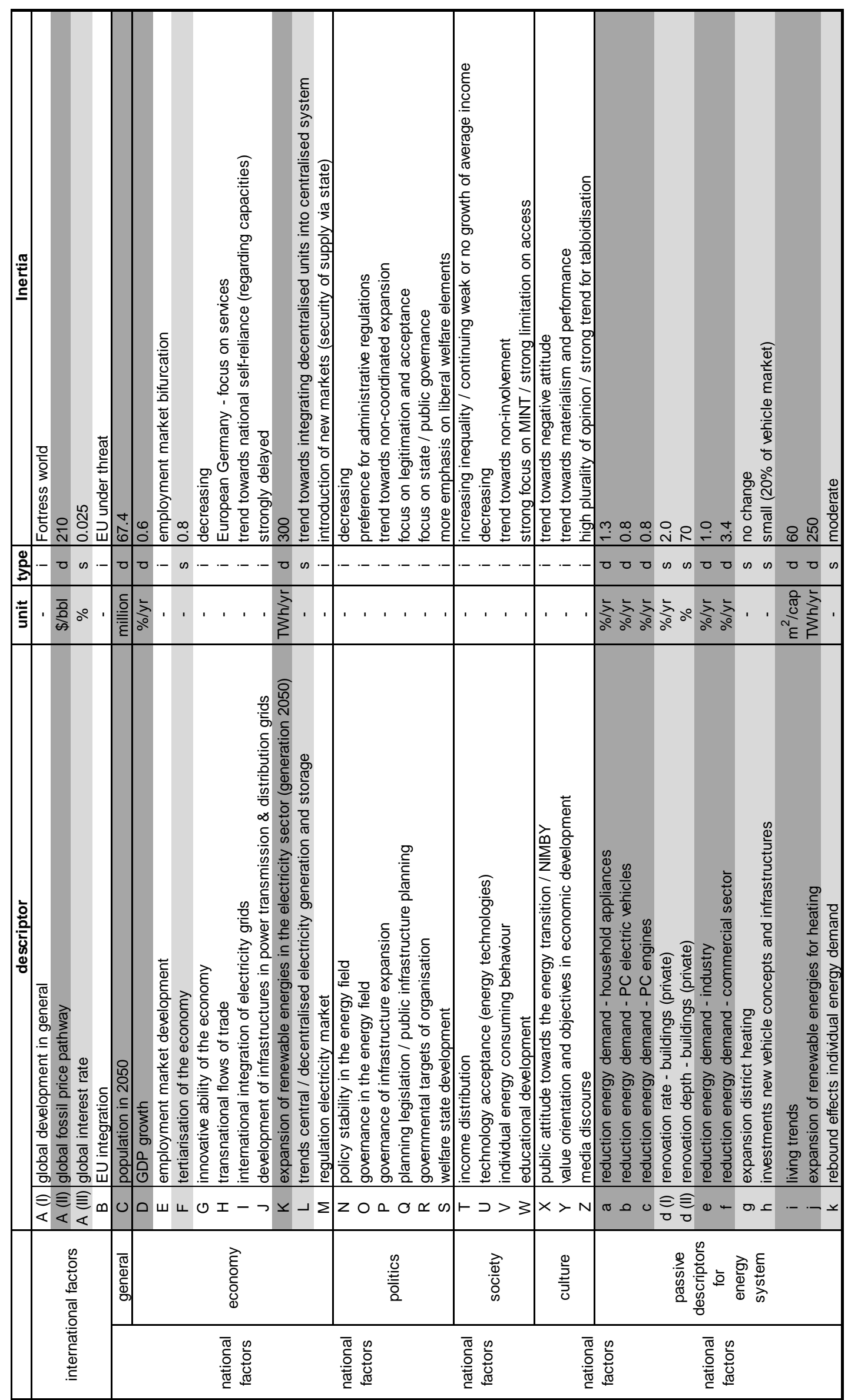

Table 2: Descriptor variants for the 'Inertia' scenario (direct/hard coupling descriptors highlighted in dark grey, soft coupling descriptors highlighted in light grey). 




Table 3: Descriptor variants for the 'Market' scenario (direct/hard coupling descriptors highlighted in dark grey, soft coupling descriptors highlighted in light grey). 




Table 4: Descriptor variants for the 'Value Shift' scenario (direct/hard coupling descriptors highlighted in dark grey, soft coupling descriptors highlighted in light grey). 


\section{Information on model parameters not directly determined by the context scenario:}

The 'hard' and 'soft' coupling factors described above to a large extent determine the final energy demand of the industrial, household, commerce and trade, and transport sectors. They further determine the amount of electricity and heat generated from renewable sources. However, the coupling factors do not determine all relevant input parameters characterizing a scenario's technical storyline. In particular, context scenarios neither define technologies used for conventional and renewable power and heat generation nor biomass consumed for energy purposes (e.g., a blended quota for biofuels). Thus, remaining relevant scenario parameters must be determined based on the two principles discussed above ( $3 \mathrm{i}$ and 3ii). This is illustrated by the three examples shown below (Figure 2 to Figure 4):

Figure 2 shows installed capacities for power generation of the four scenarios and the share of (intermittent) RES of total power generation capacity. For the three scenarios with shares of intermittent renewable power generation of greater than 60-70\% (the 'Target', 'Market', and 'Value Shift' scenarios), typical base and medium load power plants (e.g., lignite and hard coal power plants) are driven back by the system's flexibility requirements. In contrast, gas power plants serve as the backbone of conventional installed capacity, as they are capable of providing the required levels of flexibility at high shares of renewable energy.

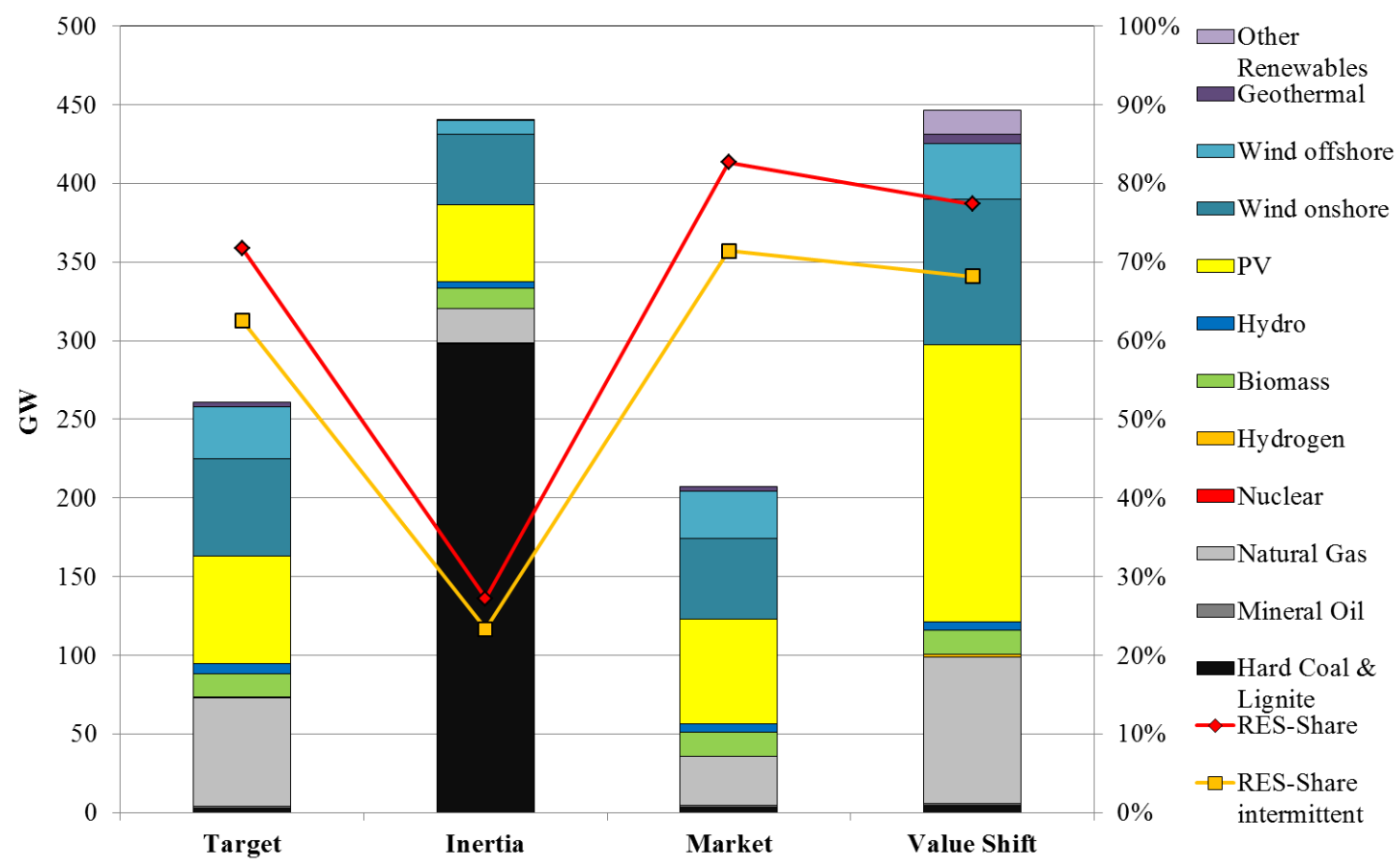

Figure 2: Installed capacities of power generation by technology and (intermittent) RES share for 2050 .

Figure 3 shows the final energy demand for space heat and hot water (SH/HW) of the residential sector differentiated by energy carrier respective technologies used. Figure 3 also shows the RES share of final energy demand for $\mathrm{SH} / \mathrm{HW}$ for this sector. Total demand is mainly constrained by the development of living space, the renovation rate and renovation depth of buildings and population development for the four scenarios (see Table 1 to Table 4). The RES share is determined from energy demand for $\mathrm{SH} / \mathrm{HW}$ and the degree of RES heat expansion observed in the scenarios. The share of district heat is determined by descriptor $\mathrm{g}$ ('expansion of district heat'). Among the scenarios, 'Target' 'Market', and 'Value Shift' district heating networks are considerably expanded. Accordingly, the share of district heat increases significantly from approximately $10 \%$ today to $28 \%$ ('Market') and $42 \%$ ('Target'). For the 'Inertia' scenario, the district heat share of total final energy consumption for $\mathrm{SH} / \mathrm{HW}$ in the residential sector remains nearly constant (12\% in 2050). Shares of other heat technologies are shaped by each scenario. Biomass consumption is lowest in the 'Target' and 'Value Shift' scenarios, as overall attitudes regarding sustainability are the strongest in these scenarios. Thus, concerns about the sustainable use of biomass for energy purposes limit bioenergy consumption in the two scenarios. Note that societal views of sustainability are not directly constrained by the context scenario 
descriptors. However, it is assumed that the combination of descriptors $\mathrm{X}$ ('public attitudes towards the energy transition') and Y ('value orientation and objectives of economic development') allows for an assessment of views of sustainability. In the 'Value Shift' scenario, the share of electric heat pumps is the highest of all scenarios. This corresponds to a strong expansion of renewable power generation (700 TWh/yr in 2050), which allows for high levels of electrification and which in turn decreases $\mathrm{CO}_{2}$ emissions generated from the heating sector.

Thus, the technology share of SH/HW for the residential sector is determined by both 'soft' and 'hard' coupling factors but also by technical constraints (principle 3i) and by constraints set by the 'spirit' of a given scenario (principle 3ii).

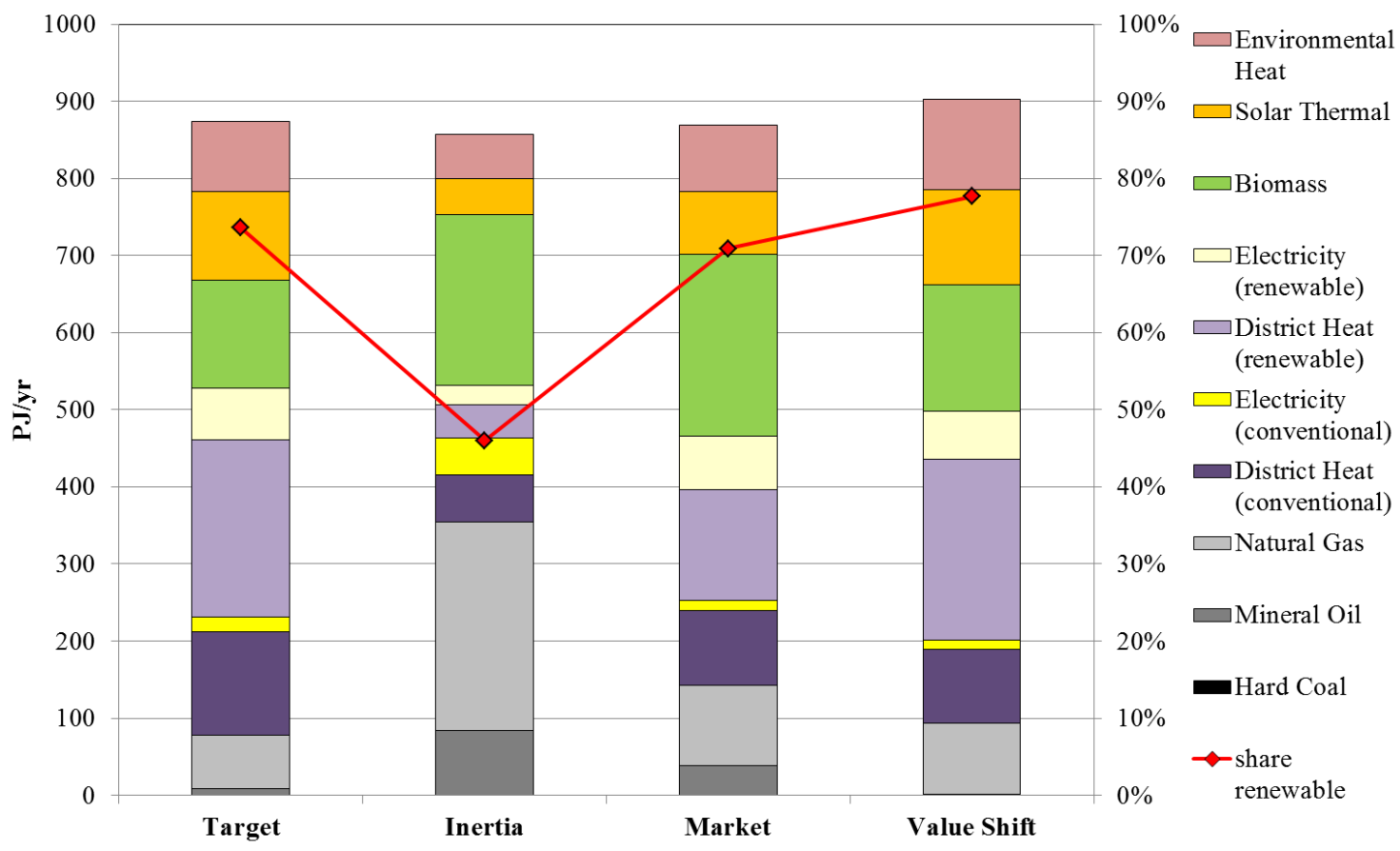

Figure 3: Final energy demand and RES share for space heat and hot water (residential sector) by energy carrier for 2050.

Figure 4 shows the final energy demand of each energy carrier for individual passenger transport and the biofuel blending quota for total diesel and gasoline. Total final energy demand is mainly determined by population development (descriptor C) and by improvements made in internal combustion engine and electric motor efficiency (descriptors b and c). The share of 'new' technologies (electric and hydrogen vehicles) is determined by descriptor $h$ ('investment in new vehicle concepts and infrastructures'). In the 'Value Shift' scenario, sustainability concerns limit biofuel consumption. Although the blending quota for this scenario is higher than it is today, low demand for diesel or gasoline results in low levels of biofuel demand. In contrast, an absence of sustainability concerns in the 'Inertia' scenario allows for a high biofuel quota with high demand for diesel and gasoline, resulting in the highest levels of biofuel consumption observed across all four scenarios. In the 'Value Shift' scenario, the share of hydrogen cars observed of all 'new' car concepts is highest. This reflects growing levels of technological acceptance (descriptor U), a trend towards technophilia (descriptor V) and improved capacities of innovation (descriptor $\mathrm{G}$ ) observed in this scenario relative to the other scenarios.

Regarding SH/HW of the residential sector, the technology mix for individual passenger transport is determined by both 'soft' and 'hard' coupling factors but also by additional technical constraints (principle 3i) and by constraints set by the 'spirit' of a given scenario (principle 3ii). 


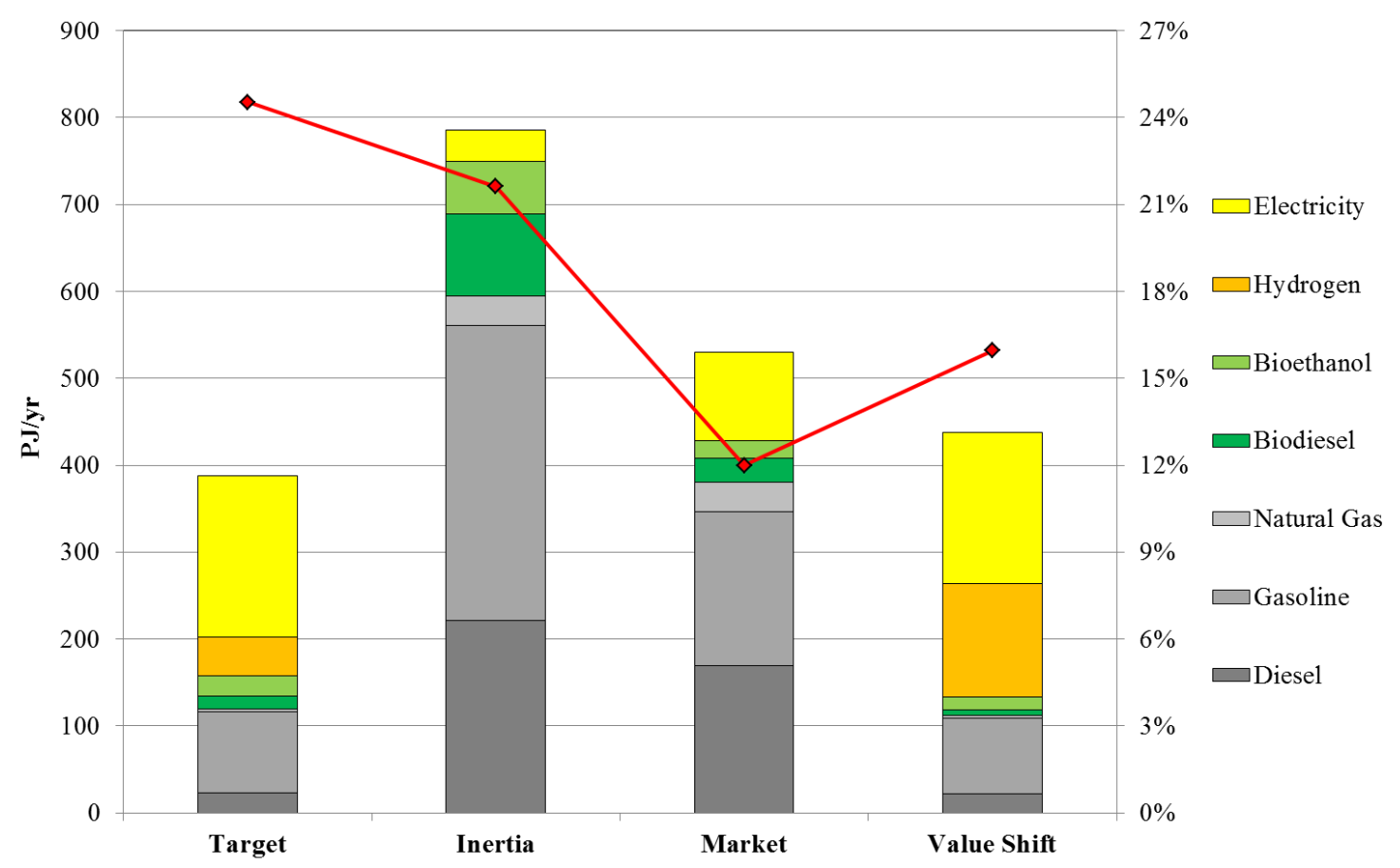

Figure 4: Final energy demand per fuel/energy carrier and biofuel blending quota for individual passenger transport for 2050 .

\section{Main differences between the scenario development using the simplified Excel tool and Mesap/PlaNet}

- Temporal resolution: The Excel tool calculates a scenario only for the target year of 2050 while the detailed scenarios developed with Mesap/PlaNet illustrate the full transformation pathway for 2015 to 2050 .

- Demand differentiated by applications: The simple Excel tool distinguishes between heat and electricity demand for private households, industry, and trade and commerce. The detailed Mesap/PlaNet model further distinguishes between space heat, process heat, hot water, air conditioning, process cooling, mechanical energy, illumination, information and communication. Furthermore, the Excel tool considers power and district heat losses, consumption, etc. in an aggregated manner.

- Technologies considered: The simple Excel tool considers fewer technologies for heat, power, and combined heat and power generation than the full Mesap/PlaNet model. With respect to heat generation, the simplified model does not differentiate between sectors. In a similar way, transport technologies are less differentiated than those considered in Mesap/PlaNet.

- Principle 3ii (determination of scenario parameters from the 'spirit' of the context scenario) cannot be applied using the Excel tool, as the modeler's interpretation of consequences of the 'spirit' of a given context scenario is not automatable.

\section{References}

Nitsch J et al. (2012) Long-term scenarios and strategies for the deployment of renewable energies in Germany in view of European and global developments. Report to the German Federal Ministry for the Environment (BMU). DLR, FhG IWES, IfnE. (in German).

Pregger T, Nitsch J, Naegler T (2013) Long-term scenarios and strategies for the deployment of renewable energies in Germany. Energy Policy, 59(0):350-360. 


\section{SM-(6) Examples of very low emission scenarios}

The set of 380 scenarios involving very low $\mathrm{CO}_{2}$ emissions $(<130 \mathrm{Mt} / \mathrm{yr})$ includes a variety of storylines and driving forces and societal conditions leading to this emission level. Some scenarios can be associated with intact societies deliberately seeking very low emissions. Others must be described as societies driven towards very low emissions by a combination of uncomfortable external pressures and internal dysfunction. However, one descriptor development is shared by all very low emissions scenarios: a small population (cf. Table 1 of the main text). This does not mean that a small population automatically leads to very low emissions; rather, the subset of 'small population' scenarios taken from the complete set of 1725 scenarios covers 73 to $734 \mathrm{Mt} \mathrm{CO}_{2}$ emissions for the year 2050 (Figure 5) (i.e., the maximum and minimum emission scenarios are related to small populations). On the other hand, moderate or large populations do not exclude substantial emission mitigation efforts. The lowest emission scenario for a moderate or large population involves the emission of $132 \mathrm{Mt} / \mathrm{yr}$ and only narrowly misses the (arbitrary) qualification for the very low emission category. In summary, a small population serves as a sort of prerequisite for very low emission scenarios. However, additional stimuli must be involved to lead society towards very low emissions. These stimuli may result from (demand driven) high fossil fuel prices, from environmental concerns, or from energy carrier supply risks as a consequence of international crises. As examples we describe the following two scenarios.

One represents the case of an intact society (Table 5, $126 \mathrm{Mt}$ ) that successfully responds to a strong increase in fossil fuel prices. The application of a market-oriented approach, a favorable setting for global prosperity and a reinvigorated EU enables strong economic growth in Germany despite its weak demographic development. This is also attributable to the presence of a highly skilled and innovative workforce and to high levels of workforce mobilization. Potential workforce scarcity ensures the strong positioning of employees within the labor market and a satisfactory yet divided pattern of income development. As a consequence, the economy and population are ready and able to assume the burdens of an energy transformation. The materialistic value orientation of this society constitutes no barrier to its capacity to manage such a transformation, as the core stimulus (strong increase of prices for fossil fuels) is an economic one and is perceived as a threat to materialistic welfare.

Table 5: Very low emission scenario. Example: Intact society

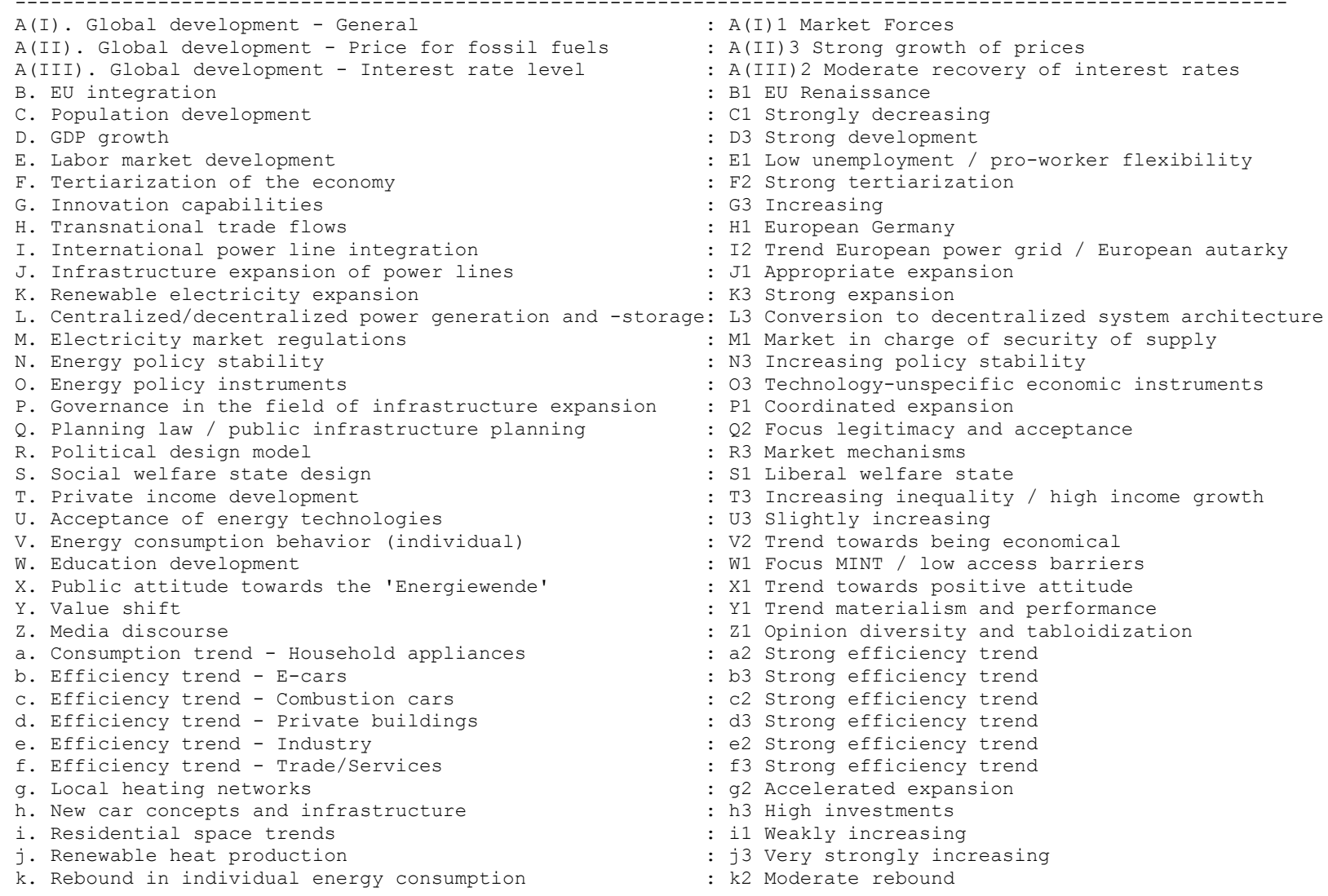


The second scenario involves a society that becomes out of step under transformative pressures (Society under pressure, Table 6, $110 \mathrm{Mt}$ ). A series of severe international crises leads to strong growth in fossil fuel prices and to uncertainties regarding constant access to energy resources. This stimulates an energy transition in Germany. At the same time, global defragmentation together with a European Union in abeyance undermines the German 'business model' of economic success. Thus, the German economy and German society are weakened just when it hurts most: in the face of an urgent need for transformation. In this critical situation, the state must at least take control of pivotal elements of the transformation to ensure a sufficient dynamic, a shift that leads in a liberalized economy to a coexistence of diverging control paradigms, spurring conflicts and frictions. Nevertheless, Germany achieves strong level of emission mitigation, albeit this is due in part to its successful energy transformation and in part to derailed efforts towards economic development.

Table 6: Very low emission scenario. Example: Society under pressure
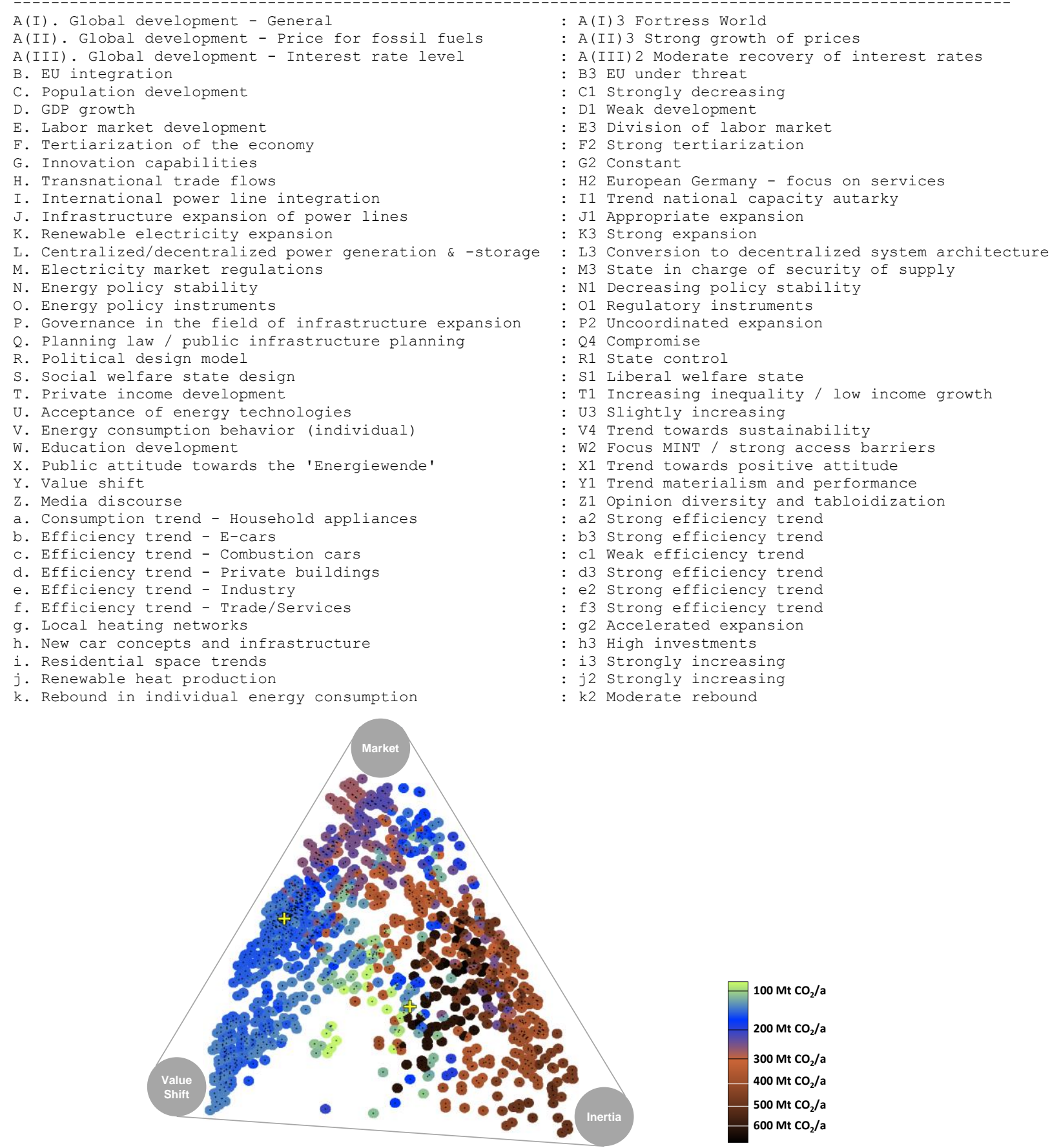

Figure 5: Landscape of societies and the selected very low emission scenarios. Yellow cross left: 'Intact society', center: 'Society under pressure'. 


\section{SM-(7) The world behind the 'Target' scenario - A socio-technical energy scenario describing the energy transformation in Germany by the year 2050}

\section{Introduction}

Among the many storylines put forth by the CIB analysis (see main article) and describing varieties of success and failure stories of different origins, this storyline features a case of success mainly driven by internal developments in Germany, though these are only possible against the background of certain international developments. This 'Target' scenario storyline (see Figure 6 and Table 1) was selected out of the full sample of approximately 1,700 CIB storylines generated by the project because its energy-economic outcomes resembles the DLR 'Long-term scenarios' (Nitsch et al. 2012 and preceding 'Leitszenarien' mentioned there), energy scenarios widely used in the German energy discourse after its publication ${ }^{1}$. Therefore, the storyline for the 'Target' scenario can broadly be seen as a reconstruction of the socio-technical background story behind the 'Long-term scenarios' revealing which societal and international framework conditions are well fitted to provoke their energy-economic developments. However, it has to be kept in mind that the 'Target' scenario presented in the main article and discussed here in the following paragraphs only resembles the 'Long-term scenarios' in many features, but is a distinct scenario for itself. Thus, the quantitative results from the 'Target' scenario shown below are not identical with the results from (Nitsch et al. 2012).

This means that the following example demonstrates a special (inverted) usage of the data provided by a CIB-plus-model analysis: Instead of selecting a certain societal development and asking for the energy-economic consequences, we are starting by a predefined normative energy scenario and inquire into the societal implications hidden behind the model results. Both directions of analysis are possible and meaningful depending on the goals of the study: they are connected to an explorative versus normative understanding of scenarios as an analytical tool.

It should be noted that the 'Target' scenario follows defined minimum targets of the German Energy Concept ('Energiekonzept', BMWi 2010) (see Table 8) reducing GHG emissions by $80 \%$ by 2050 compared to 1990 . This represents a reduction of $85 \%$ of energy-related $\mathrm{CO}_{2}$ emissions. Compared to the ambitious goals of the Paris Agreement (UNFCCC 2015), the 'Target' scenario is still a failure. Nevertheless, fundamental developments of a successful energy transition are achieved, such as significant efficiency improvements in all sectors and a massive expansion of renewable energies. These developments would have to be intensified for the target 'well below $2{ }^{\circ} \mathrm{C}$ temperature increase' and supplemented, for example, by greater use of synthetic fuels.

\section{A format for presenting socio-technical energy scenarios}

A scenario, in the end, is a narrative about the possible future development of a system, may this narrative be expressed by numbers, illustrations or text. Common model-based energy scenarios usually are depicted using quantitative data (tables and diagrams) and explanatory text. In the case of a sociotechnical energy scenario the energy narrative is expanded by a supplementing narrative about the societal developments, taking place in parallel and being intertwined with the energy developments: the 'context scenarios'. The strength of CIB based context scenarios lies in the fact that there exists (in form of the cross-impact matrix) an explicit yet qualitative 'model' about the processes which shape the societal part of the socio-technical scenarios. This model connects the societal part to the energyeconomic developments.

So the probably most modest (yet not the only) way to expand the 'classical' format of an energy scenario narration is to follow the usual course of an energy scenario report and going step by step through the energy-economic sectors. The common quantitative and verbal explanations about the technical changes are then complemented with an explanation how societal changes intervene in the

\footnotetext{
${ }^{1}$ A few other storylines were also found with high conformity with the framework assumptions of the 'Longterm scenarios', all of them very similar in their societal trend. One of them was selected here as an example for demonstrating the idea of a socio-technical energy scenario.
} 
sector, e.g. by exhibiting the partial impact models suggested by the cross-impact matrix. Following this concept, the socio-technical energy scenario presented here consists of the following elements:

- After a preliminary statement about the framework conditions, e.g. concerning the international background, each energy sector is considered step-by-step.

- In each sector, model results are shown describing the techno-economic changes using quantitative tables, diagrams, and textual explanations.

- In addition, qualitative impact diagrams show how societal drivers act on the techno-economic factors in the sector, explaining the connection between societal and technical dynamics by citing the expert statements collected during the expert interviews. To achieve lucid impact diagrams, only the most relevant promoting drivers and short summaries of their explanation text are shown. Weak promoters and also counteracting impacts are not displayed for sake of clarity (the latter are always outvoted in a consistent CIB scenario).

This format of a socio-technical energy scenario can be played out to very different text sizes. The authors may choose to present all partial impact models or only a selection. They can confine themselves to show the impact diagrams or deliver more details about the socio-technical interactions in the text, e.g. by citing the expert statements about the cross-impacts. On the energy-economic side authors can decide about the aggregation level of the model results shown and explained, ending up in short or extensive descriptions also on the techno-economic part of the narrative. In the following example we choose a rather low level of detail in order to get a reasonable text size.

\section{The 'Target' scenario: Expanding an energy-economic scenario towards a socio- technical perspective}

\section{Preliminary remarks on the context scenario identified as a consistent background storyline:}

As mentioned before the scenario analyzed here in more detail was selected out of approximately 1700 context scenarios. It can be seen as a broadly consistent societal background story behind the DLR 'Long-term scenarios' (Nitsch et al. 2012) as it matches with their framework assumptions. The descriptor configuration in this context scenario is shown in Figure 6 and in Table 13. In the heart of the storyline and its internal logical structure lies the symbiotic self-enforcement of two societal developments: constant stability of energy politics and, more or less, a preservation of the currently affirmative public attitude towards the 'Energiewende', failing in increasing this approval, but also avoiding erosion of today's positive attitudes due to coming hardships of the transformation process (see Figure 7). 


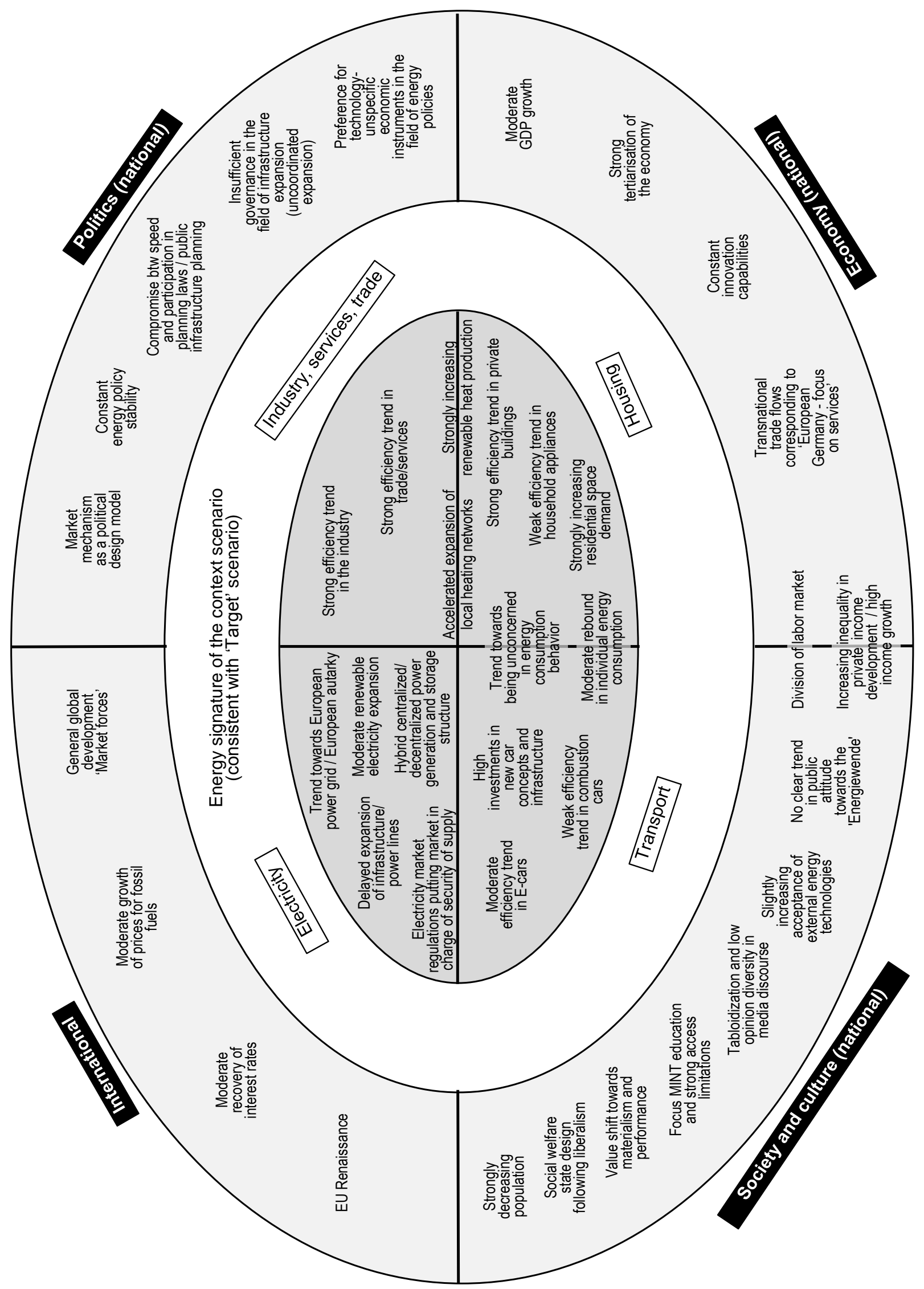

Figure 6: A context scenario describing a consistent socio-economic-political background of the 'Target' scenario. 
The power of this pair of developments as a storyline driver lies in its self-stabilizing quality: policy stability encourages a positive attitude towards a political project, or as an expert interviewed during the CIB analysis put it: 'People appreciate reliability and planning security. They prefer to place their trust in institutions whose words and deeds go hand in hand.' Vice versa, public approval eases the way for political actors to stand by their energy goals and to keep a steady hand. This self-stabilizing pair of developments builds the ground for transformative developments in many different action fields, which together form this scenario and describe a targeted pathway towards the year 2050. As a consequence of its role as a major driver of the storyline, this signature stimulates many of the other context scenario elements and, by this, it is a direct or indirect driver in many of the impact diagrams shown below.

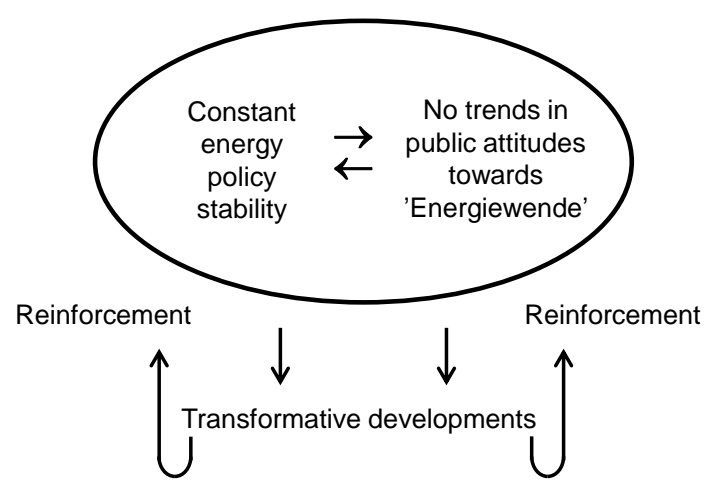

Figure 7: Signature of the storyline.
Despite the self-stabilizing quality of this pair of developments it probably will not be easy to establish this scenario signature and make it unfolding its enabling effects on the transformation process in reality: Only a very small share of the 1725 context scenarios are coined by this signature - as a rule obstructive framework conditions prevent its development or, even when established, curtail its effects. The secret of success of this scenario lies in the fact that, under the specific conditions described in this scenario, the signature produces a bundle of developments that, after unfolding, stabilize the signature instead of undermining it in the long term.

An encouraging aspect in the perspective of supporters of the 'Energiewende' is that the storyline does not assume a 'rose-colored' (i.e. overoptimistic) world: in an ideal world, policy stability as well as public affirmation would increase instead of only being stable (though on a fairly high level). In this respect (and in others) the described storyline represents a sort of 'second best world', and, as the analysis shows, a second best world is good enough for reaching at least the minimum 'Energiewende' goals if it only manages to show strength in some pivotal aspects.

\section{International background}

\begin{tabular}{|c|c|c|}
\hline & $\mathbf{2 0 3 0}$ & $\mathbf{2 0 5 0}$ \\
\hline Oil & $126 \$ / \mathrm{b}$ & $166 \$ / \mathrm{b}$ \\
\hline Gas & $11 € / \mathrm{GJ}$ & $13,8 € / \mathrm{GJ}$ \\
\hline Coal & $108 € /$ SKE & $131 € /$ SKE \\
\hline
\end{tabular}

On the global stage, the market and growth paradigm defends its role as a dominating factor. Trade barriers are removed, and developing and emerging countries are integrated more and more into the global economic structures. Global population as well as global inequality rises. The price of fossil

Table 7: Energy carrier prices (UBA 2013). energy carriers are significantly rising, avoiding extreme price levels, however. Interest rates recover and increase to a level of $2.5 \%$ real interest rates for long-term government bonds. In Europe, the EU recovers and the integration process gains strength again. This leads to productivity growth in the member states and the strengthening of integrated and coordinated climate and energy policies across the Union. With regard to the energy system this includes a European power grid integration following the goal of European energy markets (instead of national energy autarky).

These international developments serve as framework assumptions for the national context analysis. They are only one example of possible sets of international framework assumptions represented in the full sample of context scenarios. The assumptions shown above are distinguished by the fact that they were identified by the CIB analysis as a plausible international background of the national storyline described below. 


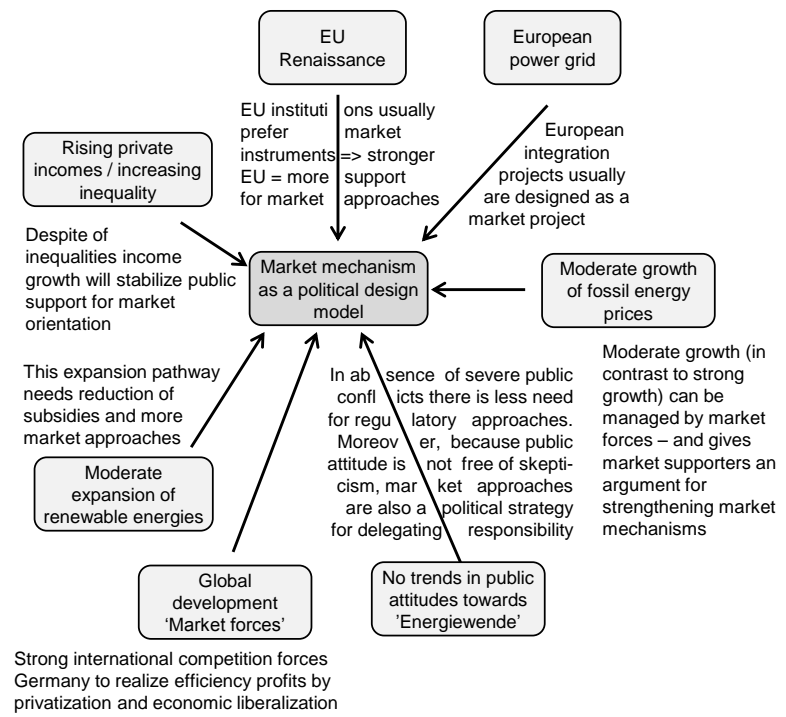

Figure 8: Partial impact model 'Political design model: market mechanism'. Only strong drivers shown.

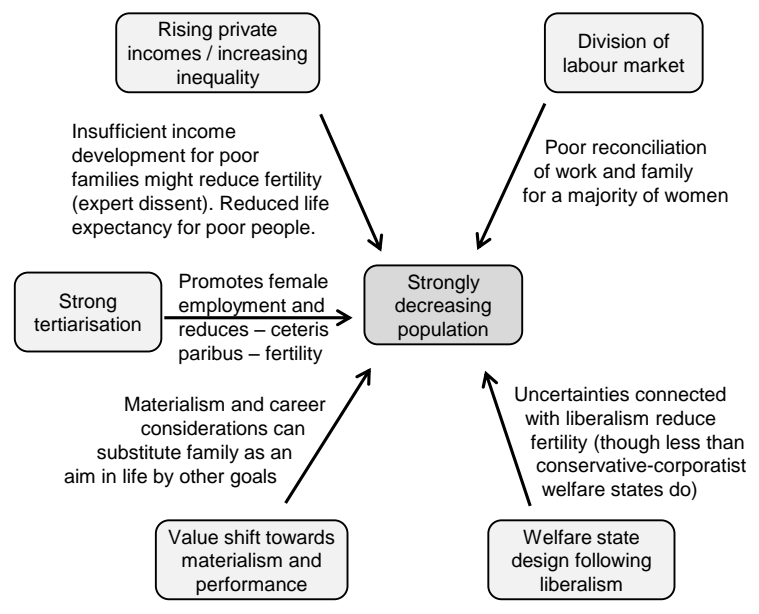

Figure 9: Partial impact model 'Strongly decreasing population'. Only strong drivers shown.

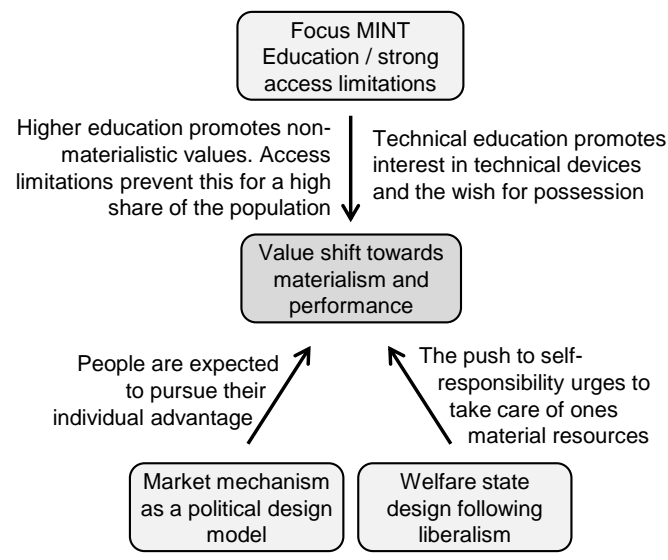

Figure 10: Partial impact model 'Direct drivers of materialism and performance values'. Only strong drivers shown.

\section{General societal development}

In a world in which the market paradigm dominates on the global scale, Germany is among the countries that follow the principles of free markets and liberalization, encouraged in parts by a reinvigorating EU. The German government trusts, as a rule, in market mechanism (Figure 8), e.g. when reorganizing the electricity market. It follows market-liberal welfare principles, prefers technology-unspecific economic instruments in energy politics (where appropriate) and tolerates an education system with significant social access barriers.

Consequences are growing income disparity, a divided labor market with high workers' flexibility (in particular for the low-skill sector), low birth rates (the aging population shrinks to 67.4 Mio. till 2050, Figure 9), a dominance of materialistic and performance oriented values in the population (Figure 10), weak intrinsic consumer interest in energy saving behavior, and by concentration effects and decreasing education level, tabloidization and a poor plurality of opinions in the media. Effective coordination of the energy infrastructure expansion is hampered too because infrastructure location decisions are more influenced by profit aspects than by balanced multilevel governance.

On the plus side Germany manages to stabilize MINT education for a sufficient share of students, innovation capacities and GDP growth on a moderate level of $1.2 \%$ per year - the latter promoted by a strong economic growth on the European and global level, increasing European trade flows. Tertiarization proceeds helping to promote female employment and partly compensating decreasing labor force in Germany. The sustained economic growth ensures that incomes are generally growing, though with different speed. Also favorable for the energy transition, public acceptance of energy technologies slightly increases, promoted among others by structural changes in the energy infrastructure and as a positive side-effect of the otherwise hindering materialistic value orientation (Figure 11). 


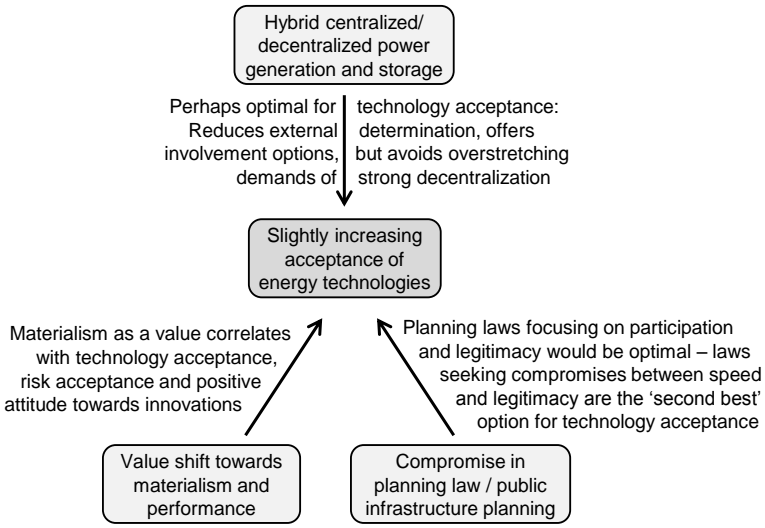

Figure 11: Partial impact model 'Direct drivers of slightly increased acceptance of energy technologies'. Only strong drivers shown.

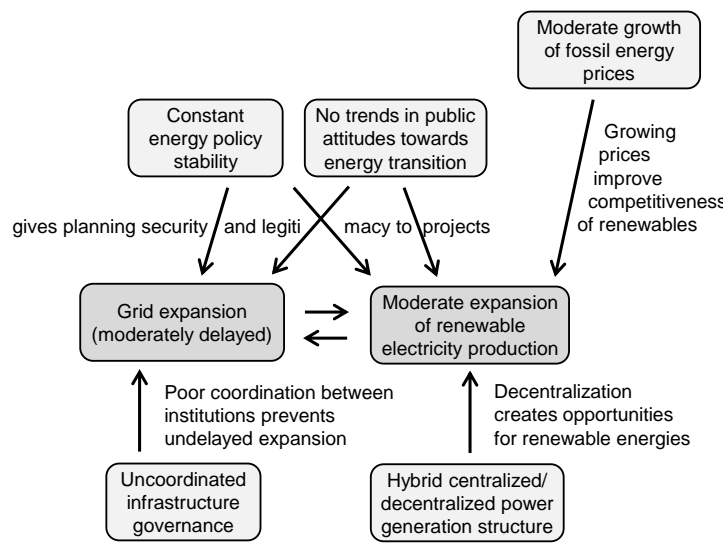

Figure 12: Partial impact model 'Direct drivers of infrastructure \& renewable electricity production'. Only strong drivers shown.

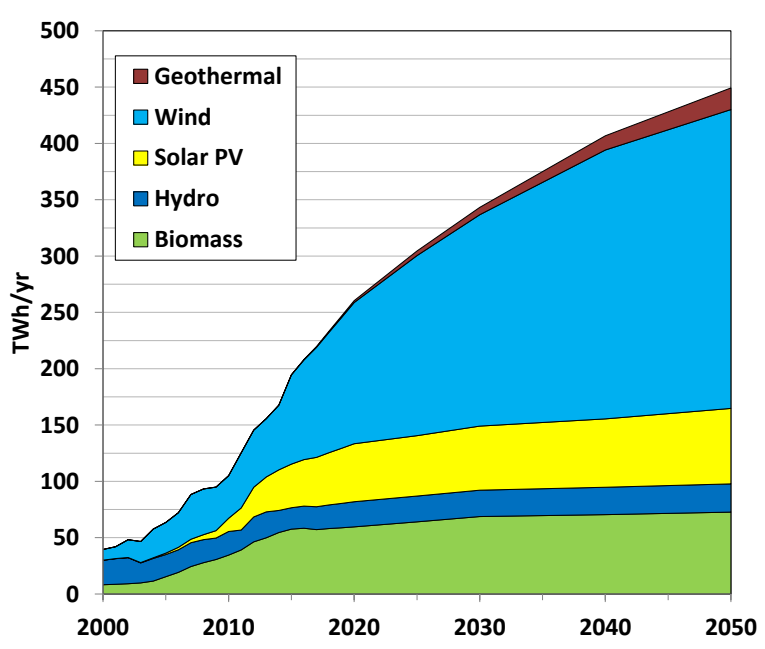

Figure 13: Renewable electricity production 2000-2050.

\section{Renewable energy production}

Renewable electricity production succeeds in maintaining the pace of the past and the production increases by approximately $8 \mathrm{TWh}$ per year on average. Major drivers of the expansion are rising prices for fossil energies, a reasonable continuing political support which results, among others, in a somewhat delayed, but steady grid extension and a public attitude which tends to be supportive, at least in principle (Figure 12 and Figure 13). Occasional attempts to further speedup the expansion fail, however, due to the limits of support of a mediocre energy policy stability. Moreover, the option of an ultra-high expansion of renewable electricity production would have needed the boost of definitely high fossil energy prices and/or a clear paradigm shift towards a widely decentralized energy system, both absent in this scenario. Further limiting factors are a limited public interest and also ability - against a background of growing income disparity - to actively engage in the energy transformation as a prosumer (limiting decentralization).

Renewable heat production, in parallel to renewable electricity production, follows a strong, yet not extreme expansion pathway, increasing at a rate of approximately $6.5 \mathrm{TWh}$ per year and partly coupled with an expansion also of heat distribution nets. Among the drivers supporting the expansion are rising prices for fossil energies, a slightly rising technology acceptance and new opportunities for renewable heat supply coming from efficiency developments in housing. A higher expansion is prevented by the low population development and a (only) stable state of energy policy stability and public attitude towards the 'Energiewende' goals. 


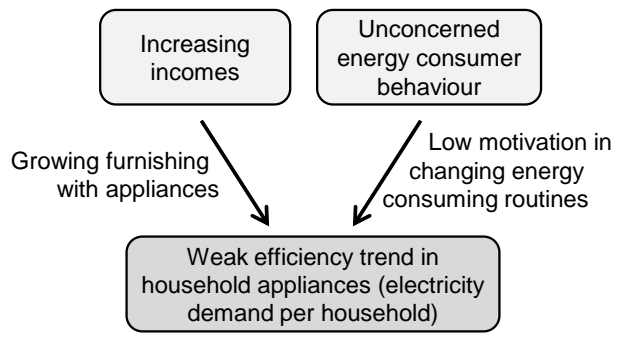

Figure 14: Partial impact model 'Direct drivers of weak efficiency trend in household appliances'. Only strong drivers shown.

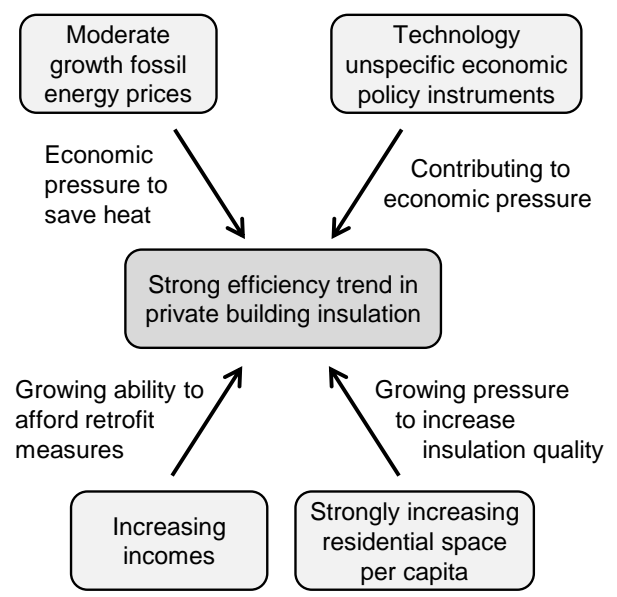

Figure 15: Partial impact model 'Direct drivers of strong efficiency trend in private building insulation'. Only strong drivers shown.

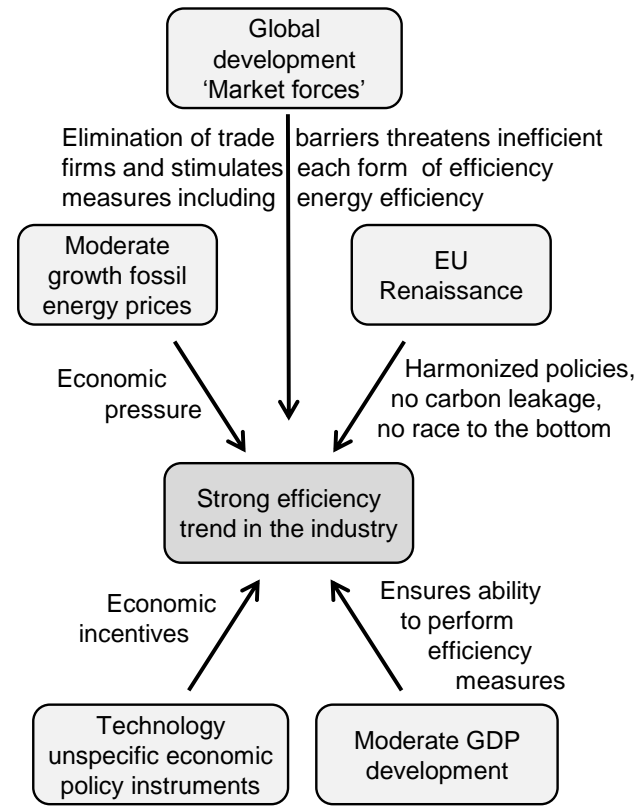

Figure 16: Partial impact model 'Direct drivers of strong energy efficiency trend in the industry'. Only strong drivers shown.

\section{Efficiency}

The societal framework conditions produce a non-uniform efficiency development across the sectors. The materialistic and consumption oriented attitudes in the majority of the population limits efficiency development where it depends on personal engagement and behavior, but enables progress where strong economic reasons advocate efficiency measures. Household appliances contribute less to the personal energy budget and in lack of other motivations efficiency growth is weak in this field (electricity consumption per household decreases by $0.6 \%$ per year, Figure 14). A stronger efficiency development is achieved in buildings ( $2 \%$ of buildings are renovated each year, reducing the energy demand of the renovated building by $70 \%$ on average, Figure 15): space heating defines a major part of the personal energy budget and against the background of rising energy prices and policy measures intensifying this effect efficiency measures are just simply a means to make the growing desire for large dwellings affordable. In the industry and in service and trade holds the same (Figure 16): the impacts of growing energy prices, growing international competition and energy policies supporting this effect speed efficiency developments to 2.3 $\%$ per year (industry) and $3.4 \%$ per year (service and trade sector).

The overall effect of those efficiency efforts can be seen in Figure 17: The total final energy consumption in the sectors residential, service and trade, and industry decreases by $43 \%$ between 2015 and 2050 (2015: around $6200 \mathrm{PJ}$, 2050: $3500 \mathrm{PJ}$ ).

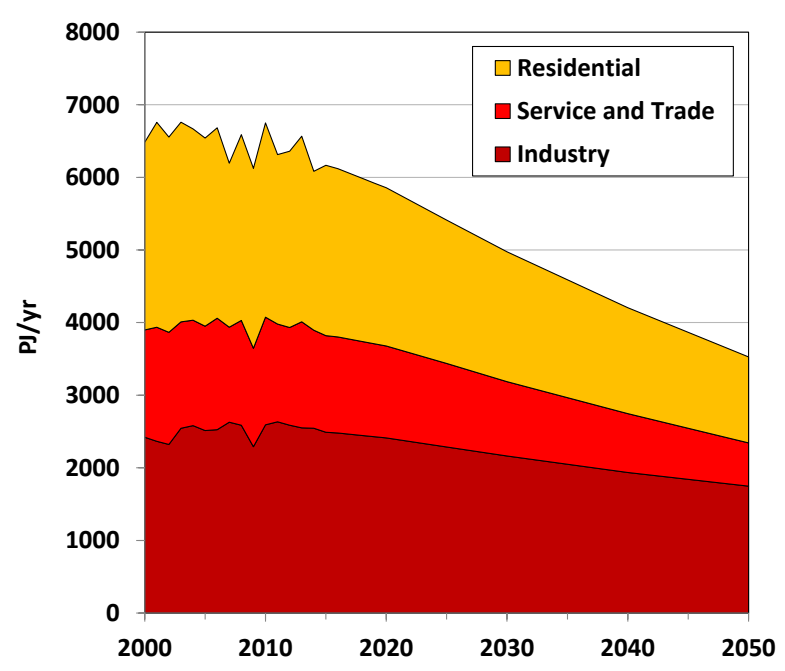

Figure 17: Total final energy demand by sector 2000-2050. 


\section{Transport}

A transition of the transport sector is an indispensable part of a successful transition of the German energy system as a whole, and the considerable emissions reduction of this scenario implies that it includes also significant changes in mobility structures and technologies. The overall pattern of the scenario, however - strongly market oriented society, consumption focused, materialistic population, the energy transition rather being a government's project - imprints itself also in the way the transport transformation takes place.

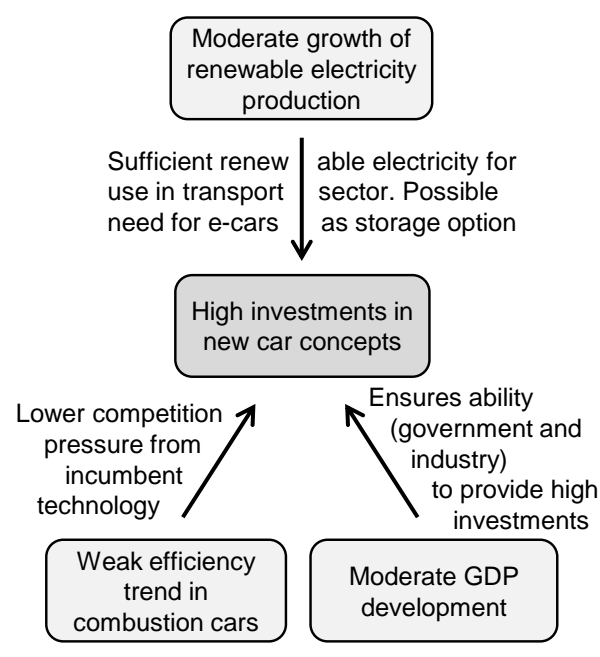

Figure 18: Partial impact model 'Direct drivers of high investments in new car concepts'. Only strong drivers shown.

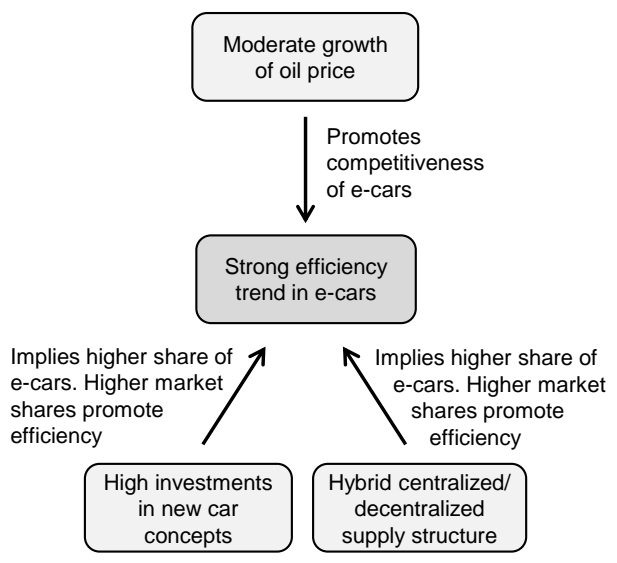

Figure 19: Partial impact model 'Direct drivers of strong efficiency trend in ecars'. Only strong drivers shown.
One formative element of the developing transport sector is that a considerable part of the population is well-off and focused on consumption enough to ignore growing fuel prices and the appeals of the government. Car manufactures respond to their demands for some time more: technological progress in combustion engines is mainly converted in size, performance and comfort and specific consumptions of traditional cars decrease only at a slow rate of $0.8 \%$ per year.

On the other hand, the goals of the energy transition make it clear to manufacturers and investors that a system transition towards e-mobility, biofuels and/or hydrogen cars will be unavoidable sooner or later. The steady extension of renewable electricity production makes it predictable when large capacities will be available also for supplying the additional demand from transportation and the storage capacity of e-car batteries or hydrogen systems will even be of systemic relevance. The satisfactory economic growth produces enough capital for broad infrastructure investments, provided investors could be convinced. It is the direction of the development of combustion cars far off the demands of the energy transition and the vacuum it creates on the field of environmental-friendly mobility that gives the needed huge investments in new car concepts the necessary security (Figure 18). Also the growing market shares of e-cars ensure fast efficiency progress for this technology (Figure 19). Figure 20 shows how these developments play out in terms of final energy demands and final energy carriers in the transport sector: final energy demand in the transport sector decreases by $46 \%$ from nearly $2600 \mathrm{PJ}$ in 2015 to slightly more than $1400 \mathrm{PJ}$ in 2050. At the same time, the share of fossil fuels in the transport energy demand decreases from $93 \%$ in 2015 to $46 \%$ in 2050 , when biofuels, electricity, and hydrogen make up $22 \%, 19 \%$, and $13 \%$ of the energy demand, respectively (see Figure 20). 


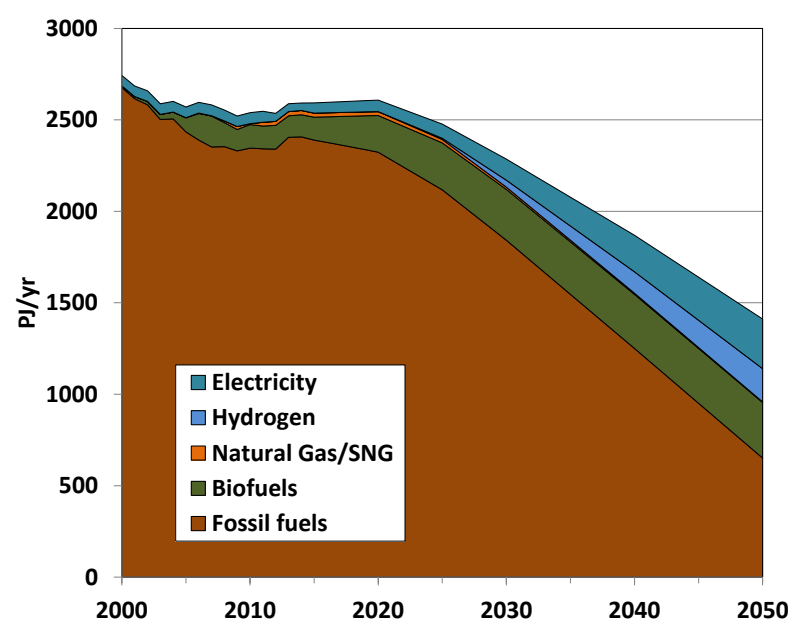

Figure 20: Final energy demand of the transport sector 2000-2050 (passengers and freight).

\section{Primary energy demand and $\mathrm{CO}_{2}$ emis- sions}

Figure 21 shows the resulting primary energy consumption ${ }^{2}$ in the 'Target' scenario differentiated by sectors. Primary energy demand decreases by $43 \%$ from approximately $13,000 \mathrm{PJ}$ in 2015 to $7070 \mathrm{PJ}$ in 2050 . This is a consequence of significant efficiency efforts in households, transport, industry, and in the service and trade sector (see discussion above), reducing final energy consumption (FEC) in these sectors. Furthermore, the shift from fossil and nuclear power production to renewable power production from mainly wind and photovoltaics (Figure 13) reduces thermal conversion losses and - consequently - primary energy demand.

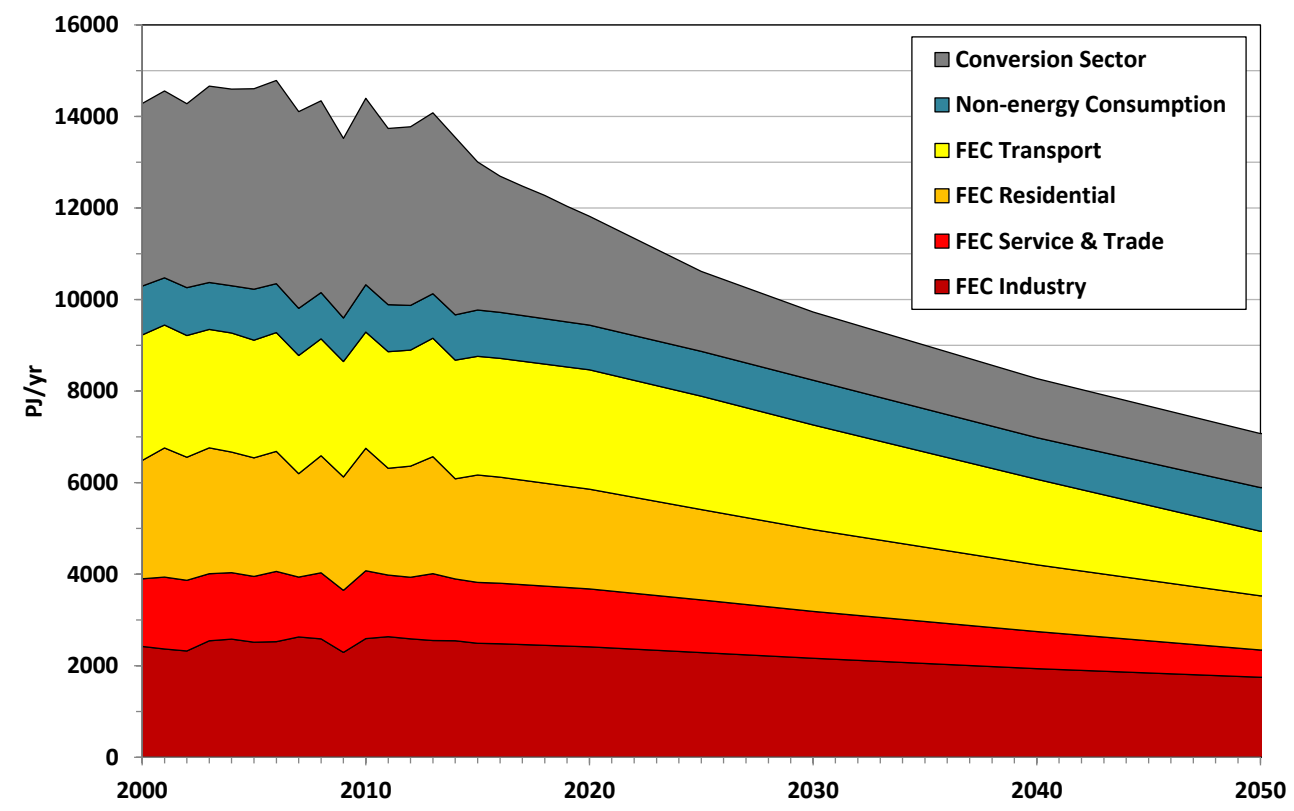

Figure 21: Primary energy demand 2000-2050 by sector.

Figure 22 shows the resulting primary energy consumption differentiated by energy carrier respectively energy source: fossil fuels - mainly natural gas and mineral oil - still contribute to $46 \%$ of the primary energy demand. They are mainly used in the transport sector, for high temperature process heat and power generation. The major renewable contributions to primary energy demand are solar (photovoltaics and solar thermal), wind, geothermal energy and biomass.

\footnotetext{
${ }^{2}$ primary energy demand calculated with the physical energy content method
} 


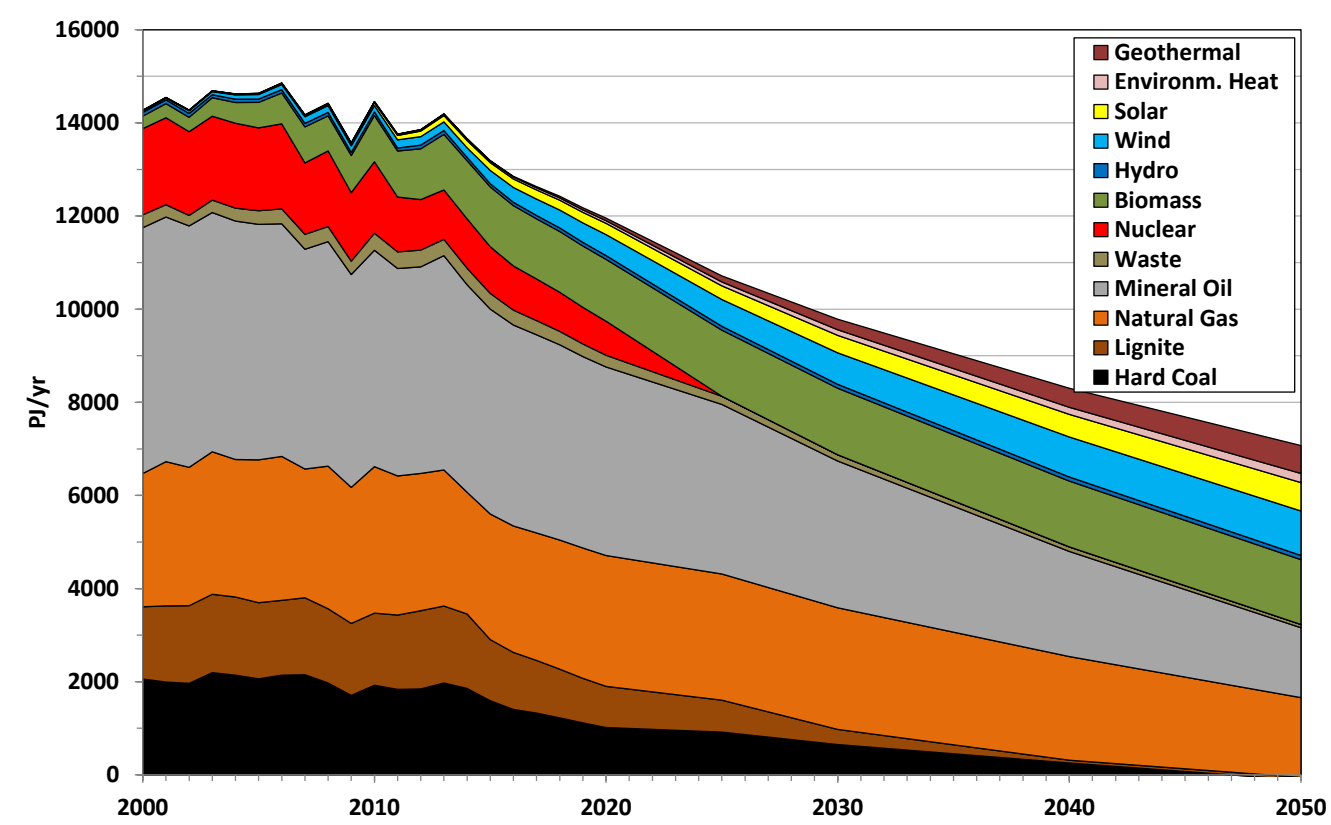

Figure 22: Primary energy demand 2000-2050 by energy carrier.

The efficiency gains, technology shifts in particular in the transport sector, and a moderate-to-strong expansion of renewable energies discussed above, result in a reduction of the annual energy-related $\mathrm{CO}_{2}$ emissions to $140 \mathrm{Mt}$ in 2050 (Figure 23). This is a reduction of more than 85\% since 1990 (the reference year for the reduction target in the German 'Energiekonzept'). The 2050 targets of the 'Energiekonzept' are thus met in this scenario (Table 8). Roughly one third of all emissions stem from the transport and conversion sectors each. Industry contributes $25 \%$ to total energy-related $\mathrm{CO}_{2}$ emissions, whereas the contributions of the residential and the service and trade sectors are small $(<5 \%)$.

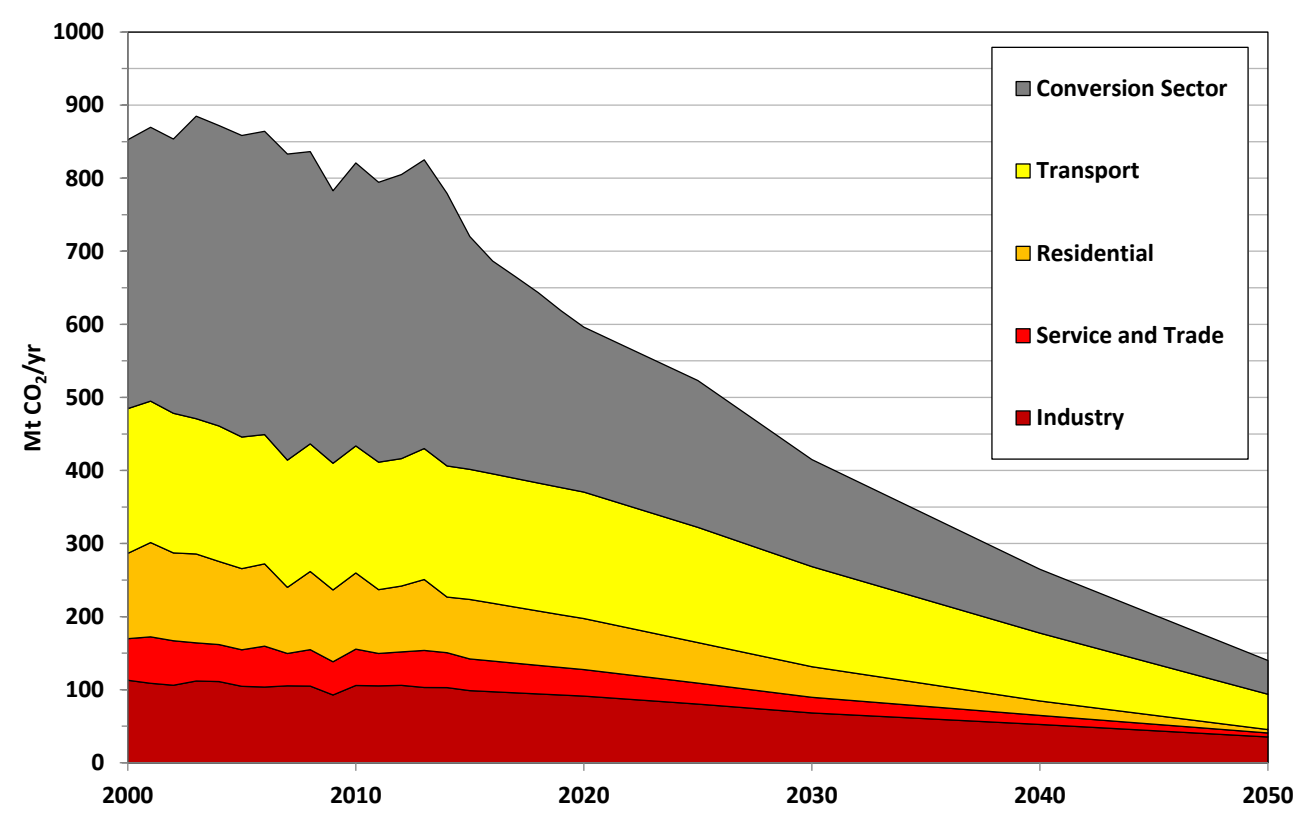

Figure 23: Energy related $\mathrm{CO}_{2}$ emissions 2000-2050.

Table 9 to Table 12 provide some more quantitative details on the 'Target' scenario. Table 13 summarizes the context scenario configuration underlying the socio-technical 'Target' scenario. 
Table 8: (minimum) targets of the energy transition according to the German 'Energiekonzept' (BMWi 2010).

\begin{tabular}{|l|c|c|c|c|}
\hline & $\mathbf{2 0 2 0}$ & $\mathbf{2 0 3 0}$ & $\mathbf{2 0 4 0}$ & $\mathbf{2 0 5 0}$ \\
\hline $\begin{array}{l}\text { GHG emissions reduction } \\
\text { (referring to 1990) }\end{array}$ & $-40 \%$ & $-55 \%$ & $-70 \%$ & -80 to $-95 \%$ \\
\hline nuclear phase out & until 2022 & & & \\
\hline $\begin{array}{l}\text { RE share (gross) final energy } \\
\text { demand }\end{array}$ & $18 \%$ & $30 \%$ & $45 \%$ & $60 \%$ \\
\hline $\begin{array}{l}\text { RE share gross electricity de- } \\
\text { mand }\end{array}$ & $35 \%$ & $50 \%$ & $65 \%$ & $80 \%$ \\
\hline $\begin{array}{l}\text { reduction primary energy de- } \\
\text { mand }\end{array}$ & $-20 \%$ & & & $-50 \%$ \\
\hline reduction electricity demand & $-10 \%$ & & & $-25 \%$ \\
\hline reduction final energy & $-10 \%$ & & & $-40 \%$ \\
\hline demand of transport sector & $-20 \%$ & & & \\
\hline $\begin{array}{l}\text { reduction heat demand (2020) } \\
\text { resp. primary energy demand } \\
\text { (2050) of buildings }\end{array}$ & & & & \\
\hline
\end{tabular}

Table 9: details on gross power generation in the 'Target' scenario, ${ }^{1}$ including biogenic waste, ${ }^{2}$ solid and liquid biomass, biogas, landfill and sewage gas.

\begin{tabular}{|c|c|c|c|}
\hline $\begin{array}{c}\text { gross power generation in TWh per } \\
\text { year }\end{array}$ & 2015 & 2030 & 2050 \\
\hline nuclear & 91.8 & 0.0 & 0.0 \\
\hline lignite & 155.0 & 42.5 & 0.0 \\
\hline of which cogeneration (CHP) & 5.4 & 2.5 & 0.0 \\
\hline hard coal & 121.7 & 55.7 & 8.2 \\
\hline of which cogeneration (CHP) & 13.4 & 8.0 & 6.3 \\
\hline natural gas & 63.6 & 110.0 & 117.1 \\
\hline of which cogeneration (CHP) & 60.6 & 84.7 & 69.8 \\
\hline oil & 5.4 & 2.0 & 1.0 \\
\hline of which cogeneration (CHP) & 2.4 & 0.8 & 0.0 \\
\hline waste $^{1}$ & 31.9 & 14.6 & 9.4 \\
\hline of which cogeneration (CHP) & 2.0 & 4.2 & 5.0 \\
\hline hydrogen & 0.0 & 0.0 & 3.5 \\
\hline of which cogeneration (CHP) & 0.0 & 0.0 & 3.5 \\
\hline photovoltaics & 38.7 & 56.9 & 67.0 \\
\hline of which rooftop systems & 36.9 & 54.1 & 64.0 \\
\hline of which ground-mounted systems & 1.9 & 2.8 & 3.0 \\
\hline wind energy & 79.2 & 187.7 & 265.3 \\
\hline of which onshore & 70.9 & 120.7 & 141.3 \\
\hline of which offshore & 8.3 & 67.0 & 124.0 \\
\hline hydro power & 19.0 & 23.4 & 25.0 \\
\hline geothermal energy & 0.1 & 6.5 & 19.2 \\
\hline ocean energy & 0.0 & 0.0 & 0.0 \\
\hline biomass $^{2}$ & 51.8 & 62.9 & 66.9 \\
\hline of which cogeneration (CHP) & 26.1 & 45.4 & 59.2 \\
\hline of which biogas (in total biomass) & 31.6 & 32.0 & 32.4 \\
\hline of which solid biomass (in total biomass) & 18.1 & 28.9 & 32.5 \\
\hline total generation & 658.2 & 562.1 & 582.6 \\
\hline
\end{tabular}


Table 10: Transport services (passenger transport) in the 'Target' scenario.

\begin{tabular}{|c|c|c|c|}
\hline $\begin{array}{l}\text { transport services - passenger transport in } \\
\text { billion pkm per year }\end{array}$ & 2015 & 2030 & 2050 \\
\hline individual road transport & 903 & 859 & 740 \\
\hline gasoline engine & 473 & 280 & 0 \\
\hline gasoline engine (hybrid) & 0 & 67 & 279 \\
\hline diesel engine & 418 & 438 & 0 \\
\hline diesel engine (hybrid) & 0 & 15 & 97 \\
\hline gas engine & 12 & 8 & 3 \\
\hline battery electric vehicle (BEV) & 0 & 43 & 287 \\
\hline hydrogen fuel cell vehicle (H2 FCEV) & 0 & 7 & 74 \\
\hline motorcycles & 19 & 19 & 17 \\
\hline gasoline engine & 19 & 17 & 13 \\
\hline battery electric vehicle (BEV) & 0 & 3 & 4 \\
\hline trains, trams etc. & 92 & 94 & 88 \\
\hline electric drive & 83 & 84 & 80 \\
\hline diesel engine & 10 & 10 & 8 \\
\hline public road transport & 76 & 69 & 64 \\
\hline diesel engine & 75 & 62 & 40 \\
\hline diesel engine (hybrid) & 0 & 2 & 4 \\
\hline battery electric vehicle (BEV) & 1 & 5 & 12 \\
\hline hydrogen fuel cell vehicle (H2 FCEV) & 0 & 1 & 8 \\
\hline aviation & 59 & 74 & 69 \\
\hline total & 1150 & 1114 & 978 \\
\hline
\end{tabular}

Table 11: Transport services (freight transport) in the 'Target' scenario.

\begin{tabular}{|lr|rrr|}
\hline \multicolumn{2}{|l|}{$\begin{array}{rrr}\text { transport services }- \text { freight transport in } \\
\text { billion tkm per year }\end{array}$} & $\mathbf{2 0 1 5}$ & $\mathbf{2 0 3 0}$ & $\mathbf{2 0 5 0}$ \\
\hline road transport & diesel engine & 431 & 480 & 337 \\
& gasoline engine & 57 & 62 & 24 \\
& diesel engine (hybrid) & 0 & 30 & 70 \\
& gasoline engine (hybrid) & 0 & 7 & 25 \\
& 0 & 9 & 23 \\
& battery electric vehicle (BEV) & 0 & 29 & 141 \\
\hline trains hydrogen fuel cell vehicle (H2 FCEV) & & $\mathbf{1 1 7}$ & $\mathbf{1 8 3}$ & $\mathbf{2 4 2}$ \\
& electric drive & 107 & 174 & 233 \\
& diesel engine & 10 & 9 & 9 \\
\hline navigation & $\mathbf{6 5}$ & $\mathbf{8 3}$ & $\mathbf{1 0 2}$ \\
\hline aviation & $\mathbf{2}$ & $\mathbf{3}$ & $\mathbf{3}$ \\
\hline \hline total & $\mathbf{6 7 1}$ & $\mathbf{8 8 6}$ & $\mathbf{9 6 7}$ \\
\hline
\end{tabular}

Table 12: prices for crude oil, natural gas and hard coal (for industry \& power plants), $\mathrm{CO}_{2}$ emission certificates (model inputs) and levelized costs of electricity (LCOE, model output).

\begin{tabular}{|l|c|rrr|}
\hline cost assumptions and results & unit & 2015 & 2030 & \multicolumn{1}{c|}{ 2050 } \\
\hline crude oil & $\$ / \mathrm{bbl}$ & 115 & 142 & 166 \\
natural gas & $€ \mathrm{ct} / \mathrm{kWh}$ & 3.23 & 4.86 & 5.98 \\
hard coal & $€ \mathrm{ct} / \mathrm{kWh}$ & 1.61 & 2.18 & 2.73 \\
\hline $\mathrm{CO}_{2}$ emission certificates & $€ / \mathrm{t}$ & 7 & 28 & 50 \\
\hline electricity $(\mathrm{LCOE})$ & $€ \mathrm{ct} / \mathrm{kWh}$ & 5.67 & 9.59 & 9.09 \\
\hline
\end{tabular}


Table 13: Context scenario configuration underlying the socio-technical 'Target' scenario.

A(I). Global development - General

A(II). Global development - Price for fossil fuels

A(III). Global development - Interest rate level

B. EU integration

C. Population development

D. GDP growth

E. Labor market development

F. Tertiarization of the economy

G. Innovation capabilities

H. Transnational trade flows

I. International power line integration

J. Infrastructure expansion of power lines

K. Renewable electricity expansion

L. Central/decentralized power generation \& -storage

M. Electricity market regulations

N. Energy policy stability

O. Energy control instruments

P. Governance in the field of infrastructure expansion

Q. Planning law / public infrastructure planning

R. Political design model

S. Social welfare state design

T. Private income development

U. Acceptance of energy technologies

V. Energy consumption behavior (individual)

W. Education development

X. Public attitude towards the 'Energiewende'

Y. Value shift

Z. Media discourse

a. Consumption trend - Household appliances

b. Efficiency trend - E-cars

c. Efficiency trend - Combustion cars

d. Efficiency trend - Private buildings

e. Efficiency trend - Industry

f. Efficiency trend - Trade/Services

g. Local heating networks

h. New car concepts and infrastructure

i. Residential space trends

j. Renewable heat production

$\mathrm{k}$. Rebound in individual energy consumption
A(I)1 Market forces

A(II)2 Moderate growth of prices

A(III)2 Moderate recovery of interest rates

B1 EU Renaissance

C1 Strongly decreasing

D2 Moderate development

E3 Division of labor market

F2 Strong tertiarization

G2 Constant

H2 European Germany - focus on services

I2 Trend European power grid / European autarky

J2 Delayed expansion

K2 Moderate expansion

L2 Hybrid structure

M1 Market in charge of security of supply

N2 Constant policy stability

O3 Technology-unspecific economic instruments

P2 Uncoordinated expansion

Q4 Compromise

R3 Market mechanisms

S1 Liberal welfare state

T3 Increasing inequality / high income growth

U3 Slightly increasing

V1 Trend towards being unconcerned

W2 Focus MINT / strong access limitations

$\mathrm{X} 2$ No clear trend

Y1 Trend materialism and performance

Z3 Tabloidization

a1 Weak efficiency trend

b2 Moderate efficiency trend

c1 Weak efficiency trend

d3 Strong efficiency trend

e2 Strong efficiency trend

f3 Strong efficiency trend

g2 Accelerated expansion

h3 High investments

i3 Strongly increasing

j2 Strongly increasing

k2 Moderate rebound

\section{References}

Nitsch J et al. (2012) Long-term scenarios and strategies for the deployment of renewable energies in Germany in view of European and global developments. Report to the German Federal Ministry for the Environment (BMU). DLR, FhG IWES, IfnE. (in German)

UNFCCC (2015) United Nations Framework Convention on Climate Change. Adoption of the Paris. Agreement. Report No. FCCC/CP/2015/L.9/Rev.1. [Internet]. 2015. Available via: http://unfccc.int/resource/docs/2015/cop21/eng/109r01.pdf.

UBA (2013) Umweltbundesamt, Dessau-Roßlau (German Environment Agency). Politikszenarien für den Klimaschutz VI - Treibhausgas-Emissionsszenarien bis zum Jahr 2030. Climate Change 04/2013.

BMWi (2010) Energiekonzept für eine umweltschonende, zuverlässige und bezahlbare Energieversorgung. Bundesministerium für Wirtschaft und Technologie. (in German) 